\title{
Operational Analysis of Fire Alarm Systems with a Focused, Dispersed and Mixed Structure in Critical Infrastructure Buildings
}

\author{
Krzysztof Jakubowski ${ }^{1}$, Jacek Paś ${ }^{2, *(D)}$, Stanisław Duer ${ }^{3}{ }^{(D)}$ and Jarosław Bugaj ${ }^{4}$ \\ 1 National Cyber Security Centre, Gen. Buka 1, 05-119 Legionowo, Poland; \\ krzysztof.jakubowski.wel@gmail.com \\ 2 Division of Electronic Systems Exploitations, Faculty of Electronics, Institute of Electronic Systems, \\ Military University of Technology, 2 Gen. S. Kaliski St., 00-908 Warsaw, Poland \\ 3 Department of Energy, Faculty of Mechanical Engineering, Technical University of Koszalin, \\ 15-17 Raclawicka St., 75-620 Koszalin, Poland; stanislaw.duer@tu.koszalin.p1 \\ 4 Division of Radiocommunication, Faculty of Electronics, Institute of Communications Systems, \\ Military University of Technology, 2 Gen. S. Kaliski St., 00-908 Warsaw, Poland; jaroslaw.bugaj@wat.edu.pl \\ * Correspondence: jacek.pas@wat.edu.pl
}

check for

updates

Citation: Jakubowski, K.; Paś, J.; Duer, S.; Bugaj, J. Operational Analysis of Fire Alarm Systems with a Focused, Dispersed and Mixed Structure in Critical Infrastructure Buildings. Energies 2021, 14, 7893. https://doi.org/10.3390/ en14237893

Academic Editor: Mohamed Benbouzid

Received: 7 November 2021

Accepted: 18 November 2021

Published: 25 November 2021

Publisher's Note: MDPI stays neutral with regard to jurisdictional claims in published maps and institutional affiliations.

Copyright: (c) 2021 by the authors. Licensee MDPI, Basel, Switzerland. This article is an open access article distributed under the terms and conditions of the Creative Commons Attribution (CC BY) license (https:// creativecommons.org/licenses/by/ $4.0 /)$.
Abstract: The article presents issues regarding the impact of operating conditions on the functional reliability of representative fire alarm systems (FASs) in selected critical infrastructure buildings (CIB). FAS should operate correctly under variable environmental conditions. FASs ensure the safety of people and CIB. Operational measurements for 10 representative systems were conducted in order to determine the impact of environmental conditions on FAS reliability. Selected operational indices were also determined. The next stage involved developing two models of representative FASs and the availability, pre-ageing time and operating process security indices. Determining operational indices is a rational selection of FAS technical and organizational solutions that enables the reliability level to be increased. Identifying the course of the FAS operating process security hazard changes in individual system lines, particularly at the initial operation stage, enables people that supervise the operation to affect operating parameters on an ongoing basis. The article is structured in the following order: issue analysis, FAS power supply in CIB, operational test results, selected FAS operating process models, determination of operational and security indices, and conclusions.

Keywords: fire alarm system; critical infrastructure; reliability requirements; construction facilities

\section{Introduction}

Fire alarm system (FAS) devices are security devices and, within the meaning of the Regulation of the European Parliament and of the Council No. 305 of 9 March 2011 (CPR), are treated and marketed in specific countries as building materials [1,2]. This is why all FAS devices and elements have been recognized as building products that are permanently built-in within a given building, such as floor beam, doors, windows, stairs, lintels or other building materials [3]. Owing to their function, namely protection of life, environment or accumulated movable and immovable property in buildings supervised by FAS, all devices, accumulator banks constituting backup power sources, FAS elements and modules are very important in terms of the fire safety of a given building or structure [4,5] (Figure 1).

The need to use a fire alarm system in a given building or structure may arise from the following provisions or assumptions:

- Legislation in force within a given country (e.g., in Poland, Regulation of the Minister of Interior and Administration of 7 June 2010, (Dz.U. 109, item 719) [1];

- $\quad$ Recommendations of competent fire safety (State Fire Service-PSP) or environmental protection authorities (e.g., District Building Supervision Office) [6,7]; 
- FAS installation and operation follows a statement or independent decision of an investor, buyer or tenant of a given building; the owner, administrator or user of a given building shall be responsible for operating the system [2].

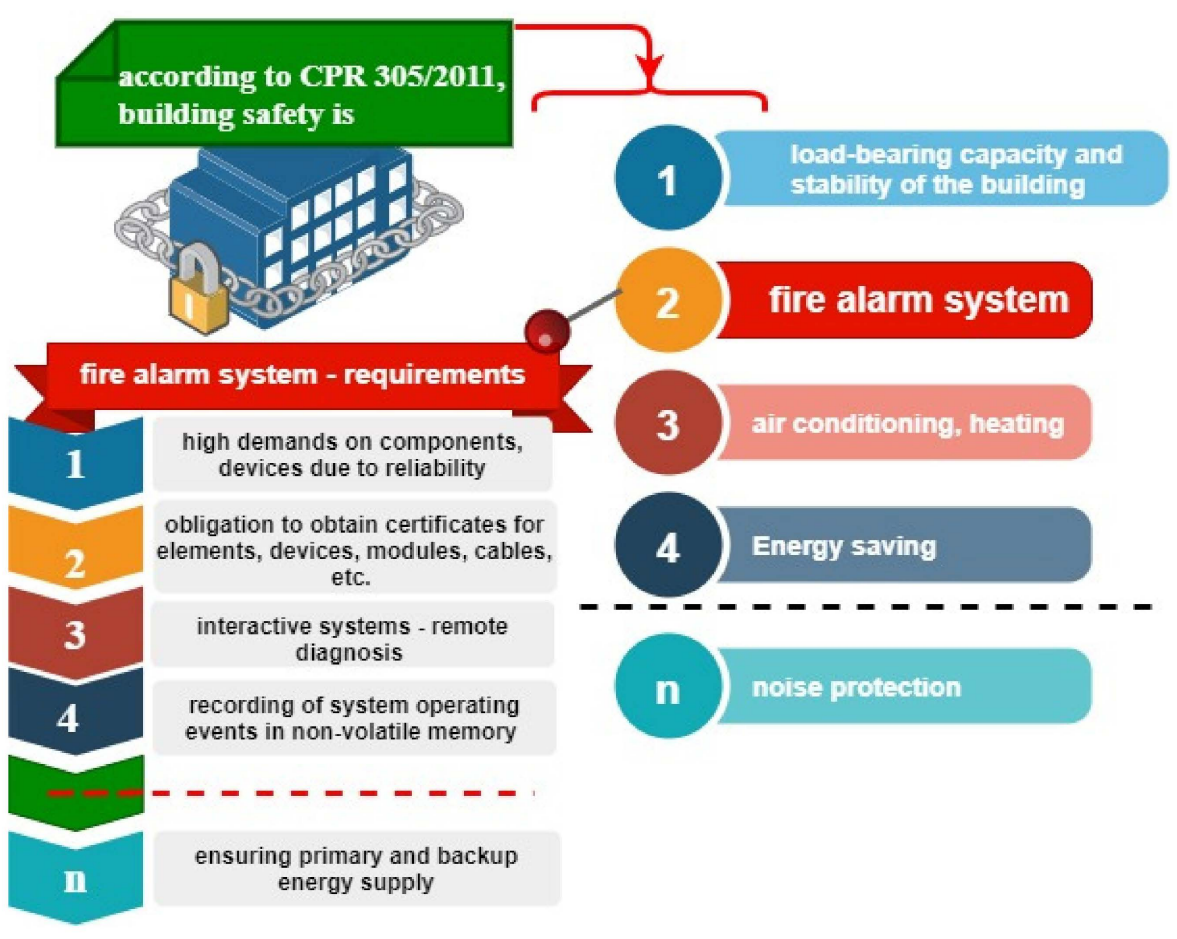

Figure 1. Requirements in the field of FAS application in buildings pursuant to CPR 305/2011.

In general, all FASs, due to their design, supervised area expressed in, e.g., $\mathrm{m}^{3}$, the number of fire zones, number of detection circuits and lines, area coverage of protected facilities and fire hazard categories can be divided to three various organization structures [8,9]:

- Fire alarm systems of focused structure, where all loops, B-type radial lines, control lines, audio and optical signaling devices, etc. are connected to a fire alarm control unit (FACU) [1,10]. A single so-called connection node is present in the FACU in such a case. The distance of the most remote locations monitored by the FACU does not exceed the permissible detection line or circuit length due to the alarm signal transmission process [11,12]. The alarm control unit contains a single so-called connection node [13] (Figure 2).

- $\quad$ Fire alarm systems of the so-called distributed and scalable structure, have an advantage of simple system expansion through adding, e.g., a control device of an alarm sub-panel to a circuit. It is achieved through hooking-up additional fire alarm system sub-panels, which are slaves to a master FACU $[14,15]$. In such a case, A-type detection circuits, B-type radial lines with detectors and audio-optical signaling devices monitor separate fire zones within buildings that may be located over a vast area. In this case, the power and backup supplies are routed to each fire alarm control unit separately, from another internal supply line (ISL) [16]. All of these measures are introduced in order to ensure reliability and due to the current power load within the facility $[17,18]$. All FACUs monitoring a given structure or such a vast area in terms of fire safety are connected through a double transmission cable, a so-called ring, for reliability purposes or operate in a so-called star system, where a master FACU is located in its central place $[19,20]$. In the case of these systems, the distance of remote locations supervised by a given FACU can exceed the permissible length of lines, detection circuits or control lines [21,22]. Due to the costs of executing a given fire system (e.g., execution of several detection lines to a remote protected part or facility) over a vast 
area, such a solution may be cheaper or more reliable than, e.g., the application of a focused FAS $[23,24]$. Due to the potential electromagnetic interference over a vast area, it is possible to connect individual FACUs using a fiber optic cable $[25,26]$ (Figure 2).

- Fire alarm systems of mixed structure are executed taking into account the sole costs of executing a given FAS, but also due to the possibility of applying various complex reliability structures when integrating the entire system $[27,28]$. In such a case, two different FAS structures shall be used, one distributed for monitoring a vast area and a high number of buildings, and a focused one [29,30]. A focusedstructure fire alarm system is in such a case connected to a distributed FACU via a transmission line. A focused or distributed system in a given building or facility may be additionally fitted with a fixed fire equipment (FFE) gas suppression system (GSS) [31,32] (Figure 2).

Currently, all FACUs used in large buildings are manufactured in the so-called modular system [33]. A FACU consists of numerous unified modules encased usually in standard metal casings [3,34]. Individually or combined into so-called sets (nodes), they can be placed at various locations of a protected building. These points may be significantly distant from each other [35,36]. The distances between individual sub-panels (nodes) may be up to $1200 \mathrm{~m}$ in the case of using a copper cable or even up to $15,000 \mathrm{~m}$ when using a single-mode optical fiber as the transmission bus [37,38]. Individual FAS subpanels within a single node are also interconnected via a common, double (redundant) digital transmission bus [39,40] (Figure 2). Individual FAS systems may be supervised through, e.g., a single alarm receiving center (ARC) that can be located within such a vast area [41]. Due to the facilities located within such a vast area, which belong to the so-called critical infrastructure, there is a possibility to install individual, less-complex ARCs to monitor selected FASs [42,43]. All ARCs are intercommunicated and have two independent tele-transmission channels, hardwired and wireless, diagnosed with a fixed or variable processing period due to a short-circuit, opening or replacement of a transmitter or receiver $[44,45]$. Telecom connections used to transmit alarm, diagnostic or damage signals to ARC or PSP are established in order to ensure an appropriate reliability level and the information transmission quality $[1,46]$.

The rest of the article is organized as follows: Section 2 is a critical review of the source literature on the current state of the problem. Section 3 contains basic information on FAS power supply, including the backup power solution, system protection method and fire switch location. Section 4 presents the results of operational tests involving two representative FAS operated in critical infrastructure facilities. Section 5 includes the developed models - operational graphs of selected FAS and computer simulation results with charts and reliability characteristics. The last, Section 6 contains conclusions arising from the conducted tests and computer simulations. 

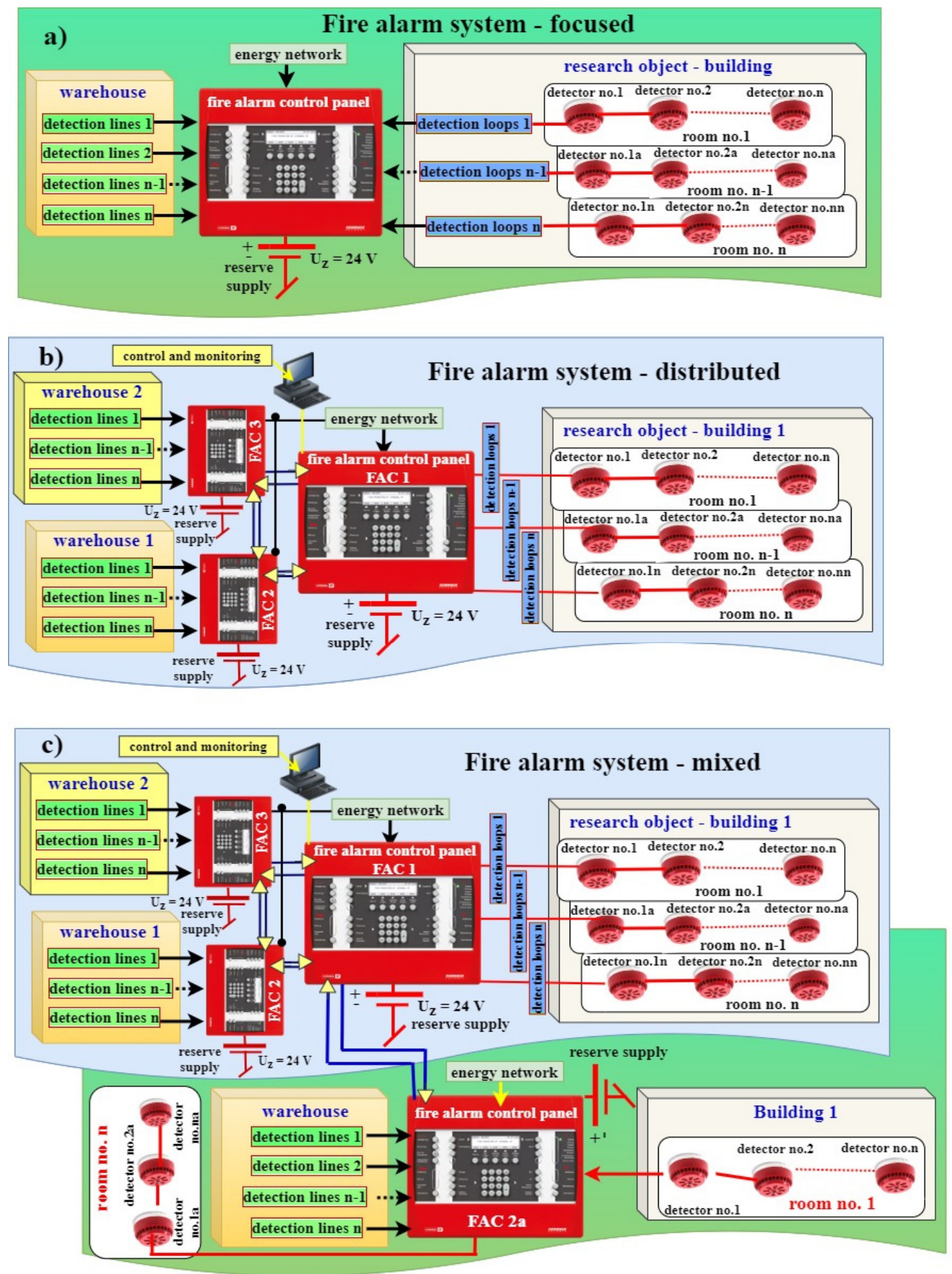

Figure 2. Configuration of fire alarm systems in buildings and structures of the so-called critical infrastructure: (a) simplestructure FAS, (b) distributed-structure FAS, (a,c) mixed-structure FAS, where $U_{z}=24$ V-supply voltage for FAS, FAC 1, FAC 2, FAC 3, FAC 2a-power supply through fire alarm control units (FACU); building, warehouse, warehouse 1, warehouse 2-critical infrastructure building areas monitored by detection circuits and lines with fire detectors of successive addresses: 1, 2, n - 1, n; 1a, 2a, n - 1a, na, . . , 1n, 2n, n - 1n, . . ,nn; room No. n-monitored only by a B-type radial line as a separate fire zone, with a switching station supplying the entire vast facility of the so-called critical infrastructure.

\section{Literature Review}

Temperature is one of the important factors within the so-called fire triangle. The authors of $[18,26,40,46]$ discussed temperature-based analysis covering the reliability of key 
electronic subsystems. This analysis enabled the optimization of, e.g., the arrangement of electronic subassemblies in the device and on the PCB, based on a conducted temperature analysis using finite element modelling (FEM) and an Ansys computer analysis. The developed method applies only to a single electronic device located at a specific place, and not electronic systems (e.g., FAS) that are spatially arranged in different rooms. Temperature is an important environmental factor determining FAS reliability. The FAS operational test conducted by the authors enables the impact of this parameter on reliability to be assessed through defining, e.g., damage intensities.

A significant issue when determining the impact of environmental factors on FAS operation is taking into account an appropriate fire detector selection $[4,11,28]$. In their work on fire detectors, the authors described dynamic tests involving the impact of fire characteristic values on the very detection of this phenomenon, as well as time. However, no reliability tests concerning, e.g., temperature and humidity properties for electronic subassemblies or the entire FAS were conducted. Through the available FAS damage statistics and the environmental conditions pertaining to the rooms, the authors were able to determine detector or element damage intensities.

Additional electronic circuits located in the detectors and alarm control panels, intended for diagnosing their technical condition, are very important with regard to FAS $[3,9,15,46]$. The articles discuss general proposals regarding measurement systems for conducting dynamic measurements of the technical conditions using various diagnostic techniques. However, the studies did not take into account the impact of signal interference arising from the application of long circuits or transmission or detection lines that are not hookedup to an alarm control panel. In this article, the authors mitigated such errors through conducting actual tests, observing alarm, damage and detection signals in control panels, where the waveform conditioning and development process takes place.

An important issue that should be taken into account within the FAS operating process are electromagnetic interference [32,43], maximum permissible temperature changes in rooms with installed detectors $[47,48]$ or accelerations of vibrations and shocks in electronic elements $[10,49]$. Within the studies discussed in the aforementioned articles, individual factors disturbing the FAS operating process are considered separately. The authors of the article conducted actual FAS tests, where the aforementioned interference was taken into account in detection and alarm signals processed in the alarm central panel. In the course of the studies conducted by the authors of the article, it was possible to physically verify, e.g., a given damage or alarm signal types in a given room, generated by interference factors.

The authors of $[15,17,50]$ describe quality and reliability studies involving the power supply of electronic and security systems. The work presented general technical requirements, but not studies on the operation of FAS power supply, especially at the initial fire stage or under any interference. During the FAS operational studies, the authors conducted tests associated with the actual power supply process for these systems through identifying changes in detection, alarm or damage currents, as well as changes to the load of an FAS power supply in all operating modes. For the purposes of the tests, the authors also took into account the transitions to FAS backup supply (battery banks) that were often executed during a forced power grid failure, as well as through deliberate shutdown. These studies were taken into account when calculating FAS operating indices.

The authors of $[8,51,52]$ addressed the issues associated with the transmission of alarm and damage signals to an alarm receiving center or the fire department. These articles only took into account the impact of reliability, quality, availability or time of transmission to remote points. The notification and service response time in the event of damage adopted for the analysis conducted by the authors was taken into account in the $\mu$ recovery parameter. It is particularly important for restoring an FAS to a state of fitness, which was taken into account in the system models developed by the authors of the article.

As stated in $[11,24,30,34]$, modern technical solutions (e.g., fuzzy sets, neural networks, multisensor, optical or laser detectors, etc.) are currently applied in order to reduce, e.g., a false alarm probability, and to increase detector operational reliability, including 
responses to various excitations of fire sensors. The FAS analysis and operational tests conducted by the authors took into account all currently operated modern detectors that are installed in detection lines and circuits. This was considered in FAS operational graphs and models in the form of the actual numerical values for the indicators of $\lambda$ damage and $\mu$ repair intensities.

Due to the particular tasks performed in facilities, FAS must be characterized by a high hardware reliability $[6,21,31,37]$, and also as a decision on the state of security within the monitored area that is worked out based on the data received from detectors $[5,11,33,34]$. In the context of the tasks described by the authors of the article, especially the second of the aforementioned aspects may be considered as a diagnostic and measurement issue, taken into account during FAS operation. For obvious reasons, the manufacturers of the analyzed FAS group do not publish information on damage, reliability and replacement time of damaged elements or the effectiveness of their solutions. The studies conducted by the authors of the article verify the application of actual FAS for the fire protection of facilities. The execution of the tests was significantly hindered due to access to FAS operated in critical infrastructure buildings. This is why the article does not state the name of the facility, manufacturer of the devices or the very organization of the FAS technical structure.

Available source literature $[13,25,53,54]$ contains various technical and operational solutions that should be taken into account when minimizing a fire in a facility or already at the evacuation stage. The authors did not address these issues; however, the FAS operational analysis itself or the test results, e.g., availability factor, can be used by designers and users of such systems to select a specific FAS manufacturer or structure. Such an analysis was not conducted during conversations with company representatives, users or the service.

\section{Power Supply Implementation for Fire Alarm Systems}

Proper FAS power supply organization is a very important issue, and for distributed systems in particular. Section 3 presents general requirements and proper organization of a power supply system, including the location of backup power sources, power protections and the main fire switch. Figure 3 also shows the flows of diagnostic signals with information on FAS technical conditions and power supply. Special process and technical solutions, including, e.g., appropriate positioning of the main fire switch, are used in order to ensure power supply continuity for FAS operated in the case of a fire [52,55] (Figure 3). So-called internal circuits supplying individual FACUs are executed in a building power system upstream of a so-called main switch, which deenergizes a given structure in the case of a fire event [54,55]. The FASs utilized primary mains supply and so-called backup power supply to ensure power supply continuity [56,57] (Figure 3).

Due to the power demand and rated currents flowing in the lines and circuits, the FAS power supply voltage is $24 \mathrm{~V}$, unlike other security systems also operated in such facilities, e.g., closed-circuit TV (CCTV), access control system (ACS) or the intrusion detection system (IDS) [50,51]. Such a solution enables individual FASs to be supplied after isolating power from the power grid, the so-called primary power [49,50]. This allows the FAS to function without drawing power from the battery bank, the capacities of which are determined in the form of developing a so-called energy balance, i.e., electricity demand, taking into account alarm and detection currents for all FAS elements and devices $[58,59]$. In the case of distributed FAS, each subsystem has an individually determined energy balance $[57,60]$. In the case of currently operated FAS, there are no legal provisions, regulations and adequate guidelines on the operational reliability of lines, elements, devices or entire technical facilities, especially within critical infrastructure $[53,59]$. 


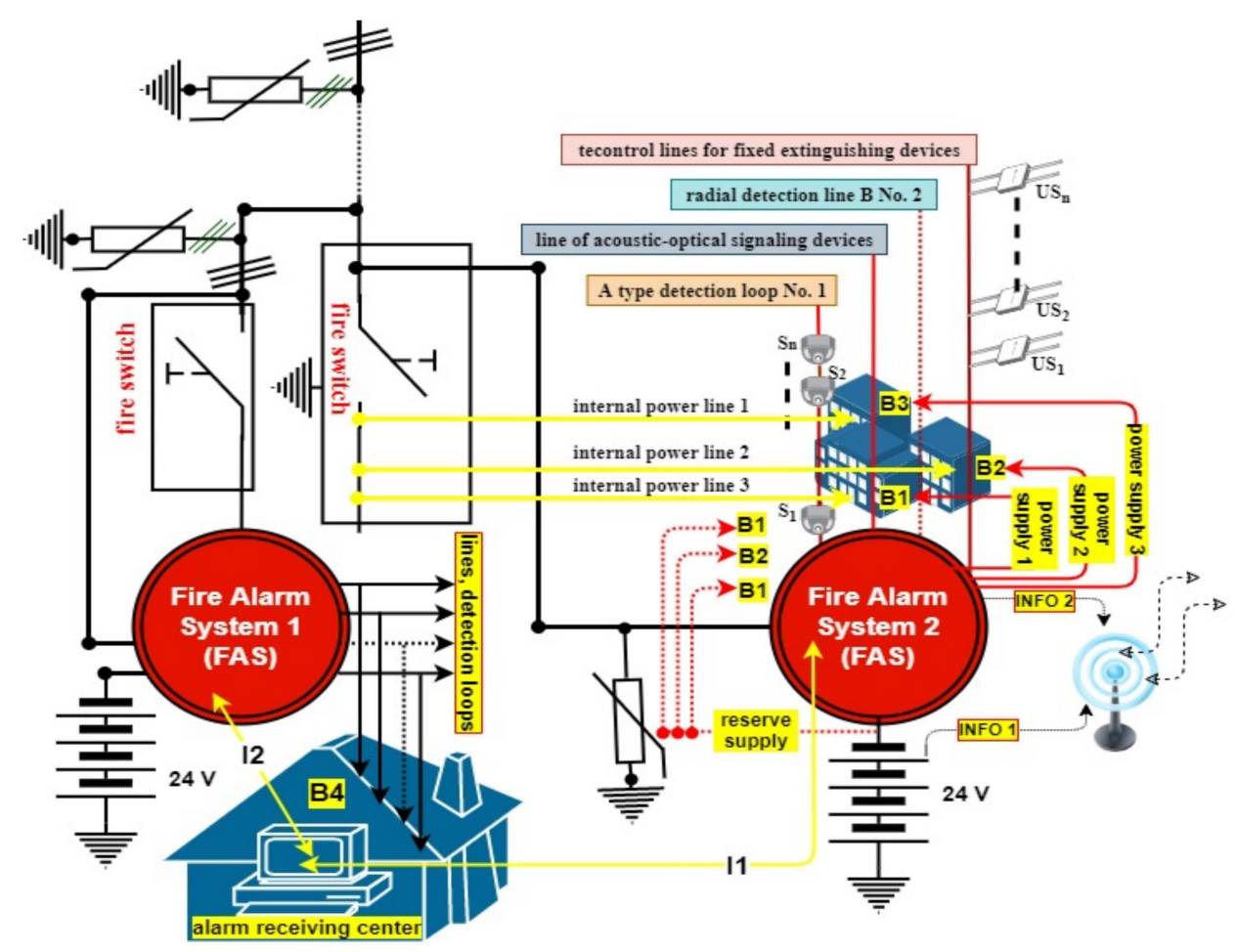

Figure 3. Power supply of fire alarm systems for B1,B2,B3-focused power supply provided by FAS2 power supply device and a $24 \mathrm{~V}$ battery bank for B4 building, B1,B2,B3 buildings of the socalled critical infrastructure, located over a vast monitored area are supplied from a single power line in the distributed mode, where $\mathrm{S} 1, \mathrm{~S} 2, \ldots$, Sn fire detectors on A-type detection line No. 1, US1, US2, ... , USn—control devices on detection line, B1,B2,B3,B4—critical infrastructure buildings, INFO1, INFO1-information (diagnostic signal) to alarm and damage signal transmission device (ADSTD) on the technical condition of primary and backup power supply systems, I1,I2-information on the technical condition of primary and backup power supply systems for the alarm receiving center, lines: A—detection circuit, B-radial line connected to a fire system control unit.

\section{Determination of Operating Process Indicators for Selected Fire Alarm Systems}

Determining FAS reliability is based on conducting limited tests of actual systems. Access to tests involving these systems is limited and difficult due to the location of FAS in critical infrastructure facilities. The manufacturers of individual FAS devices do not disclose reliability indices in their catalogues. This is why developing complete statistics regarding the occurrence of damage and the entire recovery process is an important issue. Such data is not published by leading FAS manufacturers. Operational tests covered all FAS components. The results were used as a basis to develop graphs that enable the min, max and mean to be read, as well as standard deviation for repair times. Graph 6 shows the most common damage types for all 10 conducted FAS tests. Studies aimed at determining the basic operating process indicator, e.g., reliability of different FAS structures, requires data to be obtained on the operation of these systems under various environmental conditions [2,52] (Figure 4). Environmental conditions (e.g., temperature, humidity, pressure, etc.) significantly impact such issues as damage intensity $\lambda$ of individual FAS elements, modules or devices $[11,54]$. Damage $\lambda$ intensity is also affected by variable supply voltage parameters, conducted and radiated electromagnetic interference, surges and voltage decays or dips $[34,55]$. Ten different FASs operated in various environments were studied to calculate the intensity indices for damage $\lambda$ and recovery $\mu$. Elements, modules and devices within these systems are located indoors and are exposed to direct action of a variable Earth's environment [2]. The FAS operating process analysis was conducted based on event log data recorded in the FACU. All FASs were operated within a single country, which is why it was assumed that they worked under similar environmental conditions. 
Over 80,000 entries on operating events for various manufacturers of these systems were identified in FACU permanent memories [22]. Based on FACU data and face-to-face conversations with responsible persons supervising the operating process, it can be concluded that damage most usually occurred due to an operator error-so-called human factors, such as mechanical factors-inadvertent line/circuit damage during building renovation, change of environmental conditions under which the FAS is operated, external factors not attributable to the operator, e.g., voltage decay or dip and surges in FAS power supply lines, including lightning discharges that may damage vulnerable FAS electronic elements, the implementation of an incorrect FAS design, a system that is not consistent with the recommendations of the manufacturer or the operation of individual FAS subassemblies, devices or elements $[7,22]$.

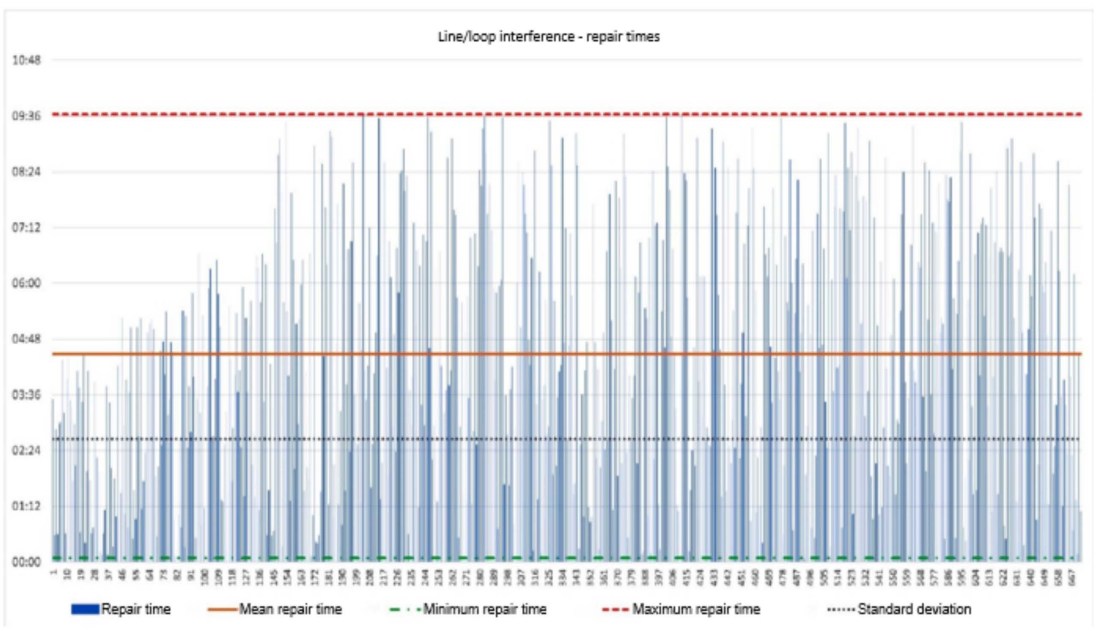

Figure 4. Repair times: line/circuit interference damage. Test results: mean repair time $268 \mathrm{~min}$, minimum repair time $5 \mathrm{~min}$, maximum repair time $578 \mathrm{~min}$, repair time standard deviation $158 \mathrm{~min}$.

Minimum, maximum and mean repair times for individual FAS elements were calculated, among others, based on the entries in the FACU event log. Standard deviation was also determined for individual repair times. Figures 4 and 5 show only selected graphs broken down by failure type identified within an FAS, while Figure 6 shows collective data for 10 FAS.

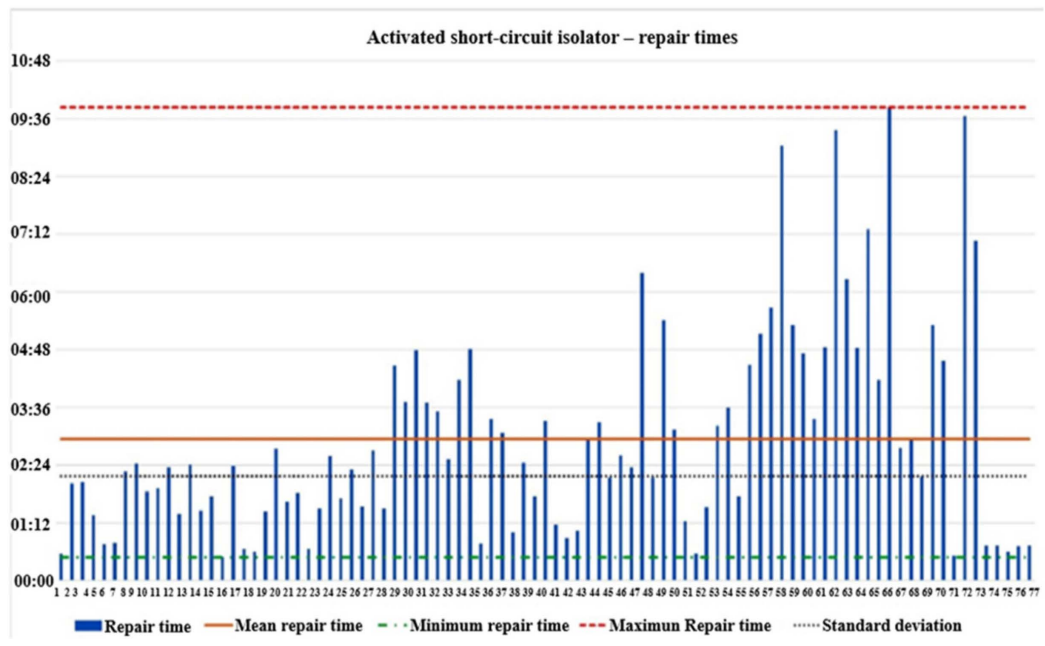

Figure 5. Repair times: activated short-circuit isolator. Test results: mean repair time $176 \mathrm{~min}$, minimum repair time $29 \mathrm{~min}$, maximum repair time $590 \mathrm{~min}$, repair time standard deviation $129 \mathrm{~min}$. 


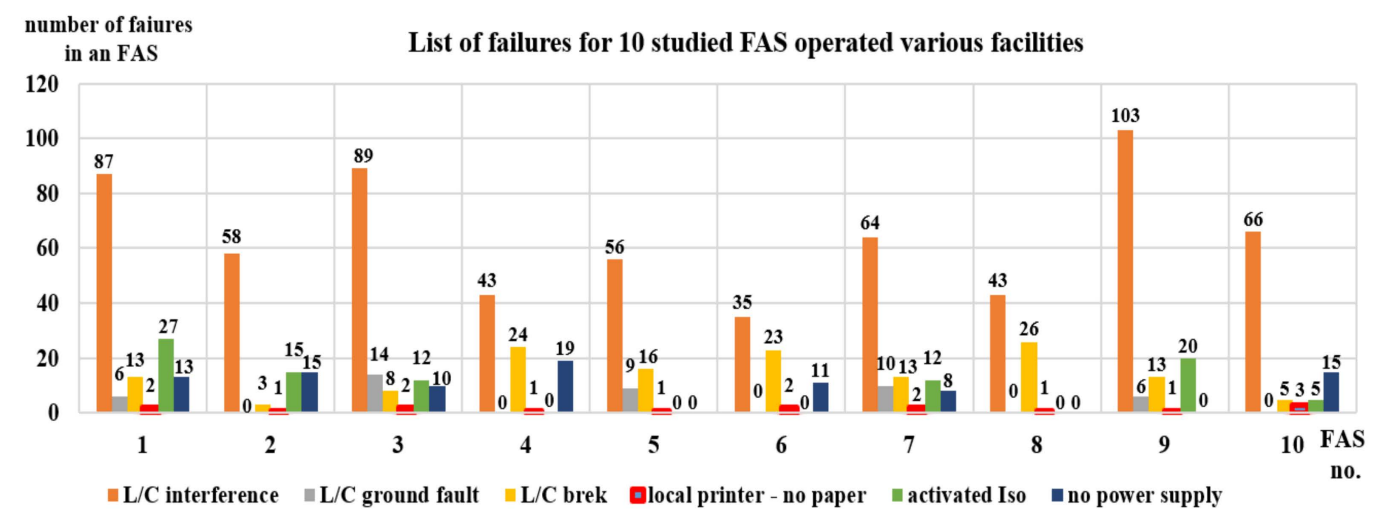

Figure 6. List of failures for 10 studied FAS operated in various facilities, where L-detection line, C-detection circuit, Iso-short-circuit isolator.

\section{Operation Process of Selected Fire Alarm Systems}

Section 5 contains developed operating graphs for two representative FASs. Actual operating data set out in Section 5 enable determining reliability indicators. The basic reliability distributions and the security unreliability function for individual FAS branches were determined in this section. Such an approach to the issue of FAS operation enables the so-called tuning at the initial stage of FAS use to be determined and allows one to assess the impact of individual lines or circuits on the total fitness of the system. The article demonstrates a limited yet representative number of FASs that are operated in critical infrastructure facilities. For the sake of operational safety and the security of information forwarded to the outside, such facilities most often operate a focused, and not a distributed FAS. A focused FAS structure is usually the case in critical infrastructure facilities (storages, shelters, etc.) where flammable materials are stored (Figure 2a), e.g., two fire detectors on a detection line are connected to the FAS FACU (Figure 7).

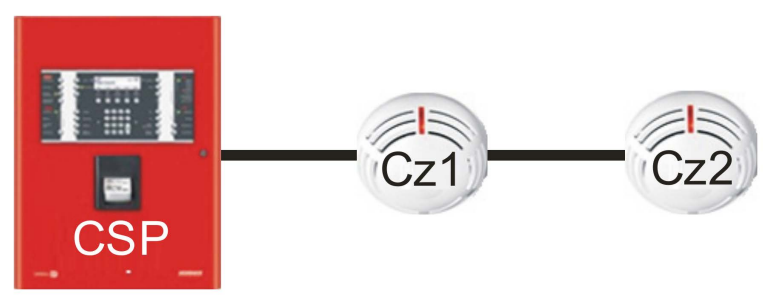

Figure 7. Simplified FAS diagram. CSP (FACU)—fire alarm control unit, Cz1, Cz2—-detectors within the system detection line.

FAS, as seen in Figure 7, can stay in eight distinguished operating states:

- $\quad$ S1-all system elements operate correctly-FACU, Cz1, Cz2;

- $\quad \mathrm{S} 2$ - the only damaged fire detector is No. 1-Cz1;

- $\quad$ S3-the only damaged fire detector is No. 2-Cz2;

- $\quad$ S4-only the fire alarm control unit-CSP is damaged;

- $\quad$ S5-both fire detectors damaged-Cz1, Cz2;

- $\quad$ S6-the only working fire detector is No. $1-\mathrm{Cz} 1$;

- $\quad$ S7-the only working fire detector is No. 2-Cz2;

- $\quad$ S8-all system elements damaged-FACU, Cz1, Cz2;

A Markov chain enables a graphic visualization of all states that an FAS can remain in. This includes the probabilities of staying in a given operating state or a transition between successive states. Given the initial assumptions (FAS-fit-S1 state) and all potential FAS states, it is possible to develop a Markov chain for the operating process of this system, as shown in Figure 8 [2,35]. As can be seen in this graph, an FAS can stay in the following states: 
- $\quad$ Full fitness $\mathrm{S}_{\mathrm{PZ}}$-if occurring in state S1;

- $\quad$ Safety unreliability $\mathrm{Q}_{\mathrm{B}}$-if occurring in state $\mathrm{S} 2$ or S3;

- Safety hazard $Q_{Z B}$-if occurring in state S4 or ... S5, S6, S7, S8.

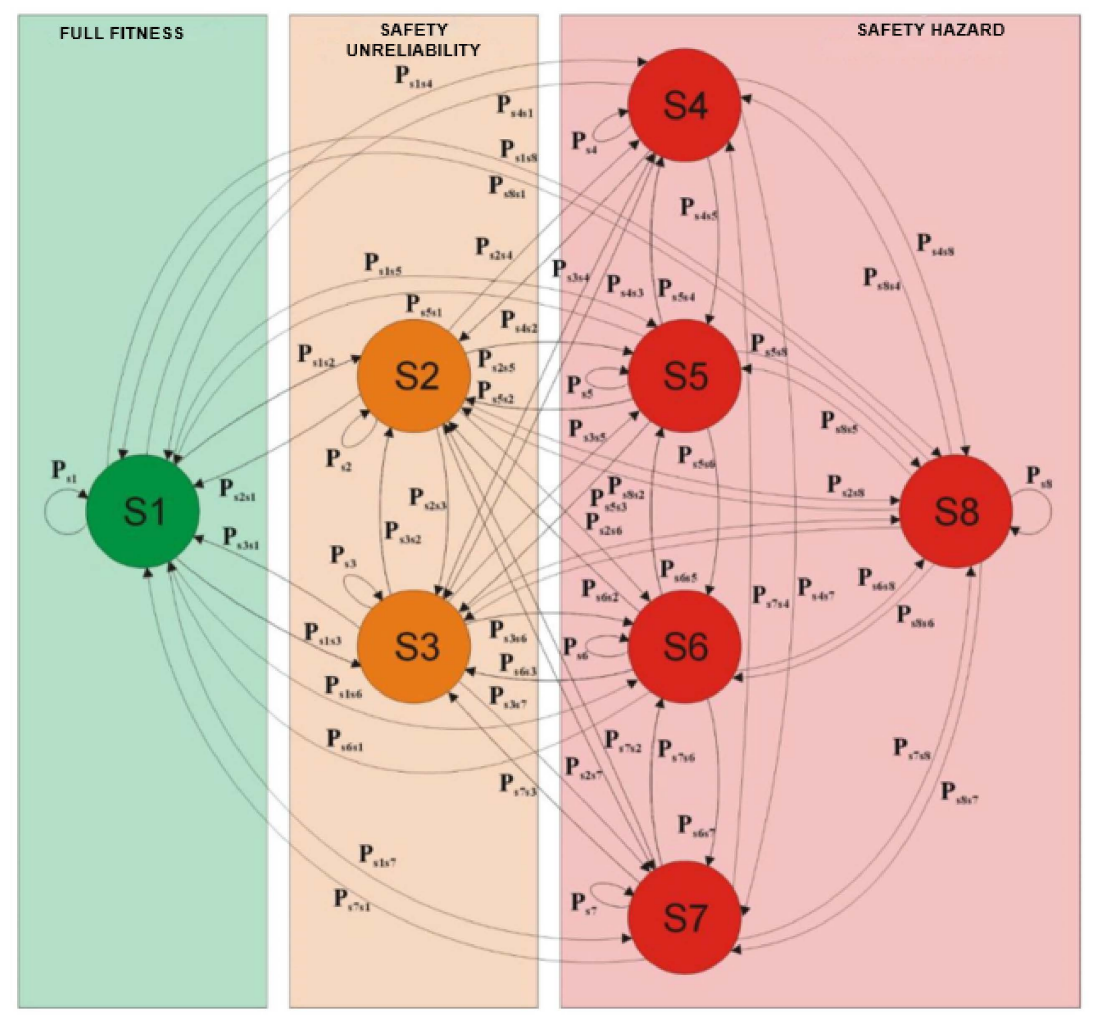

Figure 8. The Markov chain for an FAS consisting of a single FACU and two fire detectors-Cz1, $\mathrm{Cz} 2$, where $\mathrm{P}_{\mathrm{S} 1 \mathrm{~S} 2}$ is the probability of transition between state $\mathrm{S} 1$ and $\mathrm{S} 2, \mathrm{P}_{\mathrm{S} 2 \mathrm{~S} 1}$ is the probability of transition between state $\mathrm{S} 2$ and $\mathrm{S} 1$, etc., $\mathrm{P}_{\mathrm{s} 1}, \mathrm{P}_{\mathrm{s} 2}, \ldots$, etc. are the probabilities of the FAS remaining in the distinguished states $\mathrm{S} 1, \mathrm{~S} 2, \ldots$, etc.

The transitions between successive FAS states are described as probability functions, e.g., probability of a system's transition from state $S_{x}$ to state $S_{y}$, marked in Figure 8 as $\mathrm{P}_{\mathrm{SxSy}}$. By using the aforementioned damage and repair probability functions, it is possible to determine all possible transitions. Due to the fact that damage to FAS elements is independent of each other, through the application of design and organizational solutions, the probability of transition $\mathrm{P}_{\mathrm{S} 1 \mathrm{~S} 2}$ can be expressed by a product of the probability of damage to fire detector No. 1 (Cz1), and the probability of correct operation of the FACU and fire detector No. 2 (Cz2); this is determined by Equation (1).

$$
P_{S 1 S 2}(t)=R_{C S P}(t) \cdot Q_{C z 1}(t) \cdot R_{C z 2}(t)
$$

By proceeding analogously in the case for other probabilities of leaving the S1 state, it is possible to determine and calculate individual probabilities occurring in the case of a focused, simple FAS, i.e., determine other $\mathrm{P}_{\mathrm{S} 1 \mathrm{~S} 3}, \mathrm{P}_{\mathrm{S} 1 \mathrm{~S} 4}, \mathrm{P}_{\mathrm{S} 155}, \mathrm{P}_{\mathrm{S} 156}, \mathrm{P}_{\mathrm{S} 1 \mathrm{~S} 7}, \mathrm{P}_{\mathrm{S} 1 \mathrm{~S} 8}$.

By adopting the operating data obtained in the course of studying 10 various FAS designs, it is possible to determine the intensities of damage $\lambda$ and repairs $\mu$ for various components of such a technical structure, operated for a selected period of time. The damage $\lambda$ and recovery $\mu$ intensities were determined based on studies and observations of the FAS operating process. They respectively amount to, for a focused FAS-CSP (FACU), Cz1, $\mathrm{Cz} 2$, which is determined by Expressions (2)-(4).

$$
\lambda_{\mathrm{CSP}}=1.25478 \cdot 10^{-7}\left(\frac{1}{\mathrm{~h}}\right) ; \mu_{\mathrm{CSP}}=0.1306\left(\frac{1}{\mathrm{~h}}\right)
$$




$$
\begin{aligned}
& \lambda_{\mathrm{Cz} 1}=4.48762 \cdot 10^{-6}\left(\frac{1}{\mathrm{~h}}\right) ; \mu_{\mathrm{Cz} 1}=0.1818\left(\frac{1}{\mathrm{~h}}\right) \\
& \lambda_{\mathrm{Cz} 2}=3.14687 \cdot 10^{-6}\left(\frac{1}{\mathrm{~h}}\right) ; \mu_{\mathrm{Cz} 2}=0.1810\left(\frac{1}{\mathrm{~h}}\right)
\end{aligned}
$$

where $\lambda_{\mathrm{CSP}}-\mathrm{FACU}$ damage intensity, $\mu_{\mathrm{CSP}}-\mathrm{FACU}$ recovery intensity, $\lambda_{\mathrm{Cz} 1} \mathrm{Cz} 1$ damage intensity, $\mu_{\mathrm{Cz} 1}-\mathrm{Cz} 1$ recovery intensity, $\lambda_{\mathrm{Cz} 2}-\mathrm{Cz} 2$ damage intensity, $\mu_{\mathrm{Cz} 2} \mathrm{Cz} 2$ recovery intensity.

Figures 9-11 show selected $\mathrm{P}$ probabilities as a function of the time of transition from the $\mathrm{S} 1$ state to other states, and FAS residence times in various states, for $\mathrm{t}=8760 \mathrm{~h}$.

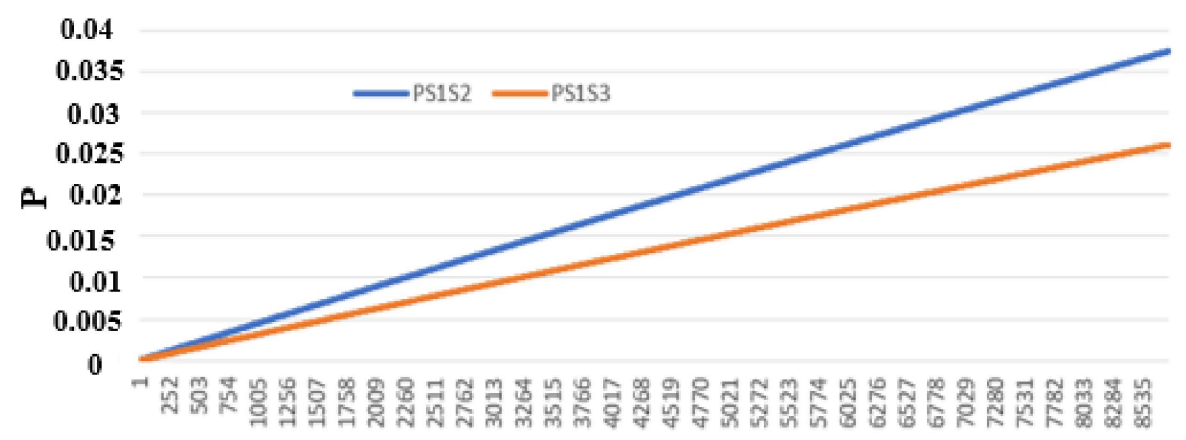

thl]

Figure 9. Probability of FAS transitioning from state S1 to states S2 and S3.

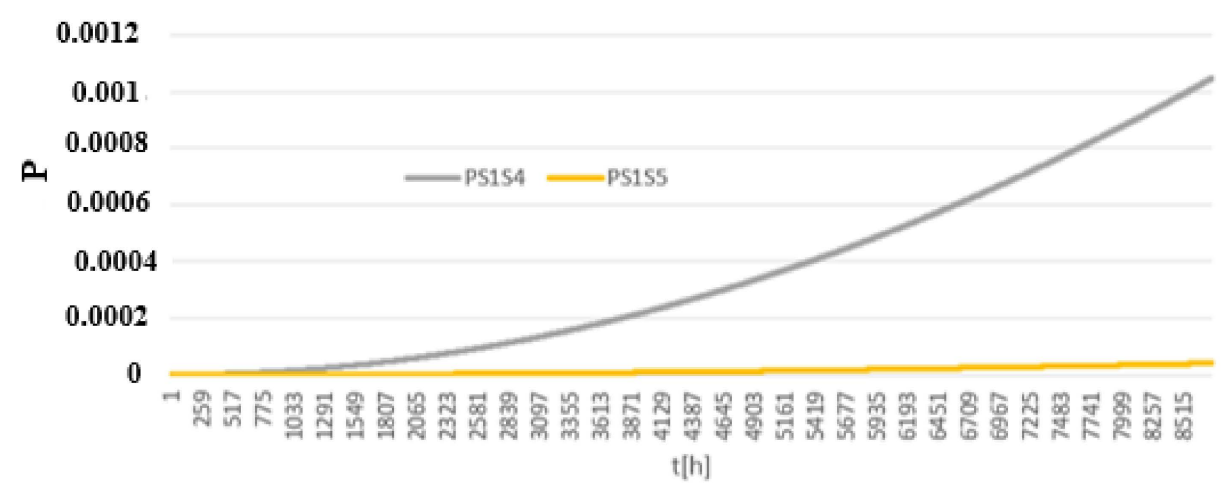

Figure 10. Probability of FAS transitioning from state S1 to states S4 and S5.

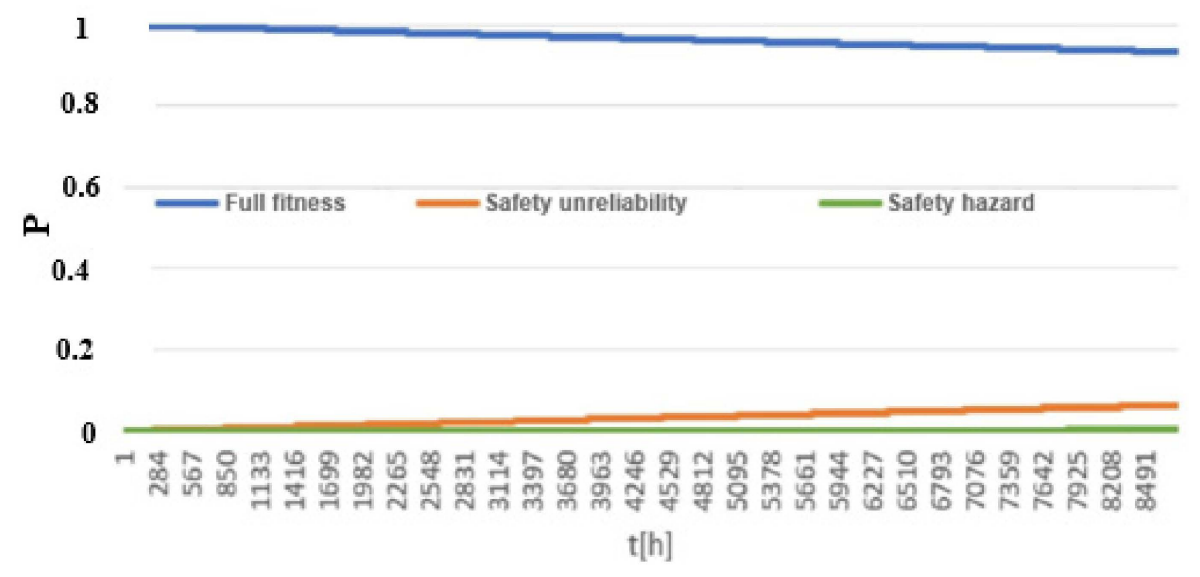

Figure 11. Probability functions for a system staying in one of the three primary states.

Based on the obtained results, it is possible to calculate the A availability coefficient for FAS, according to Expression (5).

$$
\mathrm{A}=\frac{\mathrm{T}}{\mathrm{T}+\mathrm{Q}}
$$


where A-FAS availability coefficient; T-mean duration of FAS staying in a state of full fitness or safety unreliability (mean probability); Q-mean duration of the system staying in the state of safety hazard (mean probability).

In the FAS in question, they respectively amounted to the following, according to Expression (6):

$$
-\mathrm{T}=0.966768623 ;-\mathrm{Q}=0.000090143 ;-\mathrm{A}=0.999098569
$$

In order to calculate the time spent in one of the three general safety states, it will be necessary to calculate the mean probability of staying in a given state. In the FAS in question, they respectively amounted to the following:

- $\quad \mathrm{M}_{\mathrm{PZ}}=0.966768623$ mean probability of staying in a state of full fitness;

- $\quad \mathrm{M}_{\mathrm{ZB}}=0.032329946$ mean probability of staying in a state of safety unreliability;

- $\mathrm{M}_{\mathrm{Z}}=0.0000901431$ mean probability of staying in a state of safety hazard.

For the adopted focused-type FAS operation time $t=8760 \mathrm{~h}$, the times of staying in individual states are respectively determined by Expression (7):

$\mathrm{T}_{\mathrm{PZ}}=\mathrm{M}_{\mathrm{PZ}} * \mathrm{t}=8468.8934[\mathrm{~h}] ; \mathrm{T}_{\mathrm{ZB}}=\mathrm{M}_{\mathrm{ZB}} * \mathrm{t}=283.21323[\mathrm{~h}] ; \mathrm{T}_{\mathrm{Z}}=\mathrm{M}_{\mathrm{Z}} * \mathrm{t}=7.8965997[\mathrm{~h}]$

An FAS staying in a state of full fitness is most probable, while reaching a state of safety hazard, i.e., FACU damage, is less probable. The least probable state that may occur within the FAS in question is S8, i.e., damage to all system elements- the state of FACU, $\mathrm{Cz} 1$ and $\mathrm{Cz} 2$ unfitness. A specified number of detectors, manual call points (MCP) on detection lines, are used in the case of an FAS that is used to protect buildings and rooms and communication routes therein.

This is determined by the maximum area monitored by lines connected to a FACU. Figure 12 shows a simplified diagram of an FAS consisting of B-type lines with connected detectors, MCP, control modules or audio and optical devices. Various technical and organizational solutions that enable the preset fitness level to be achieved for the entire facility are used due to FAS operational reliability [54]. This is why the application of redundancy and a fail-safe principle in such systems already at the design stage leads to a situation in which a single FAS element or device failure does not result in so-called critical or catastrophic damage $[20,53]$. This is particularly important when developing a so-called FAS control matrix that takes into account the so-called fire scenario [10].

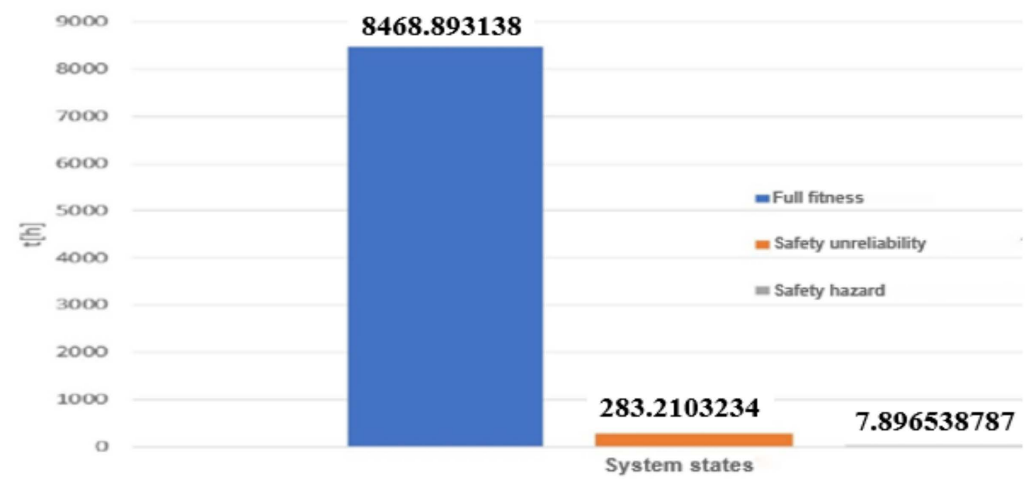

Figure 12. Focused FAS time of residence in various safety states.

The application of various solutions that take into account FAS reliability enables fire scenarios to contain operational events that involve so-called indirect system unfitness states or safety hazard states $\mathrm{Q}_{\mathrm{ZB}}(\mathrm{t})$; they are often called in source literature as efficiency failure $[2,55]$. There are only two basic operating states in technical systems without redundancy. These are a state of full fitness $R_{o}(t)$ and a state of safety unreliability $\mathrm{Q}_{\mathrm{B}}(\mathrm{t})[22,45]$ (Figure 8). In order to identify fire alarm system unreliability indices, it is nec- 
essary to determine the environmental conditions under which such technical structures are operated $[56,57]$.

These environmental parameters significantly impact the damage intensity coefficient $\lambda$ for elements, devices and modules making up the FAS. For the sake of fire safety within Btype detection lines (Figure 13), there are restrictions to the number of installed detectors (a maximum of 32) and MCPs (10 units) [2,45,58]. Individual fire zones within an FAS shall be separated by a short-circuit isolator (Figure 13). Figure 13 shows a focused FAS monitoring a building $[22,59,60]$. It consists of two separate fire zones located in the building and warehouse [2]. In order to ensure power supply security, the FAS was equipped with a backup power supply in the form of a battery bank with a capacity determined through calculating the energy balance that takes into account monitoring and alarm currents for individual elements of this system [61].

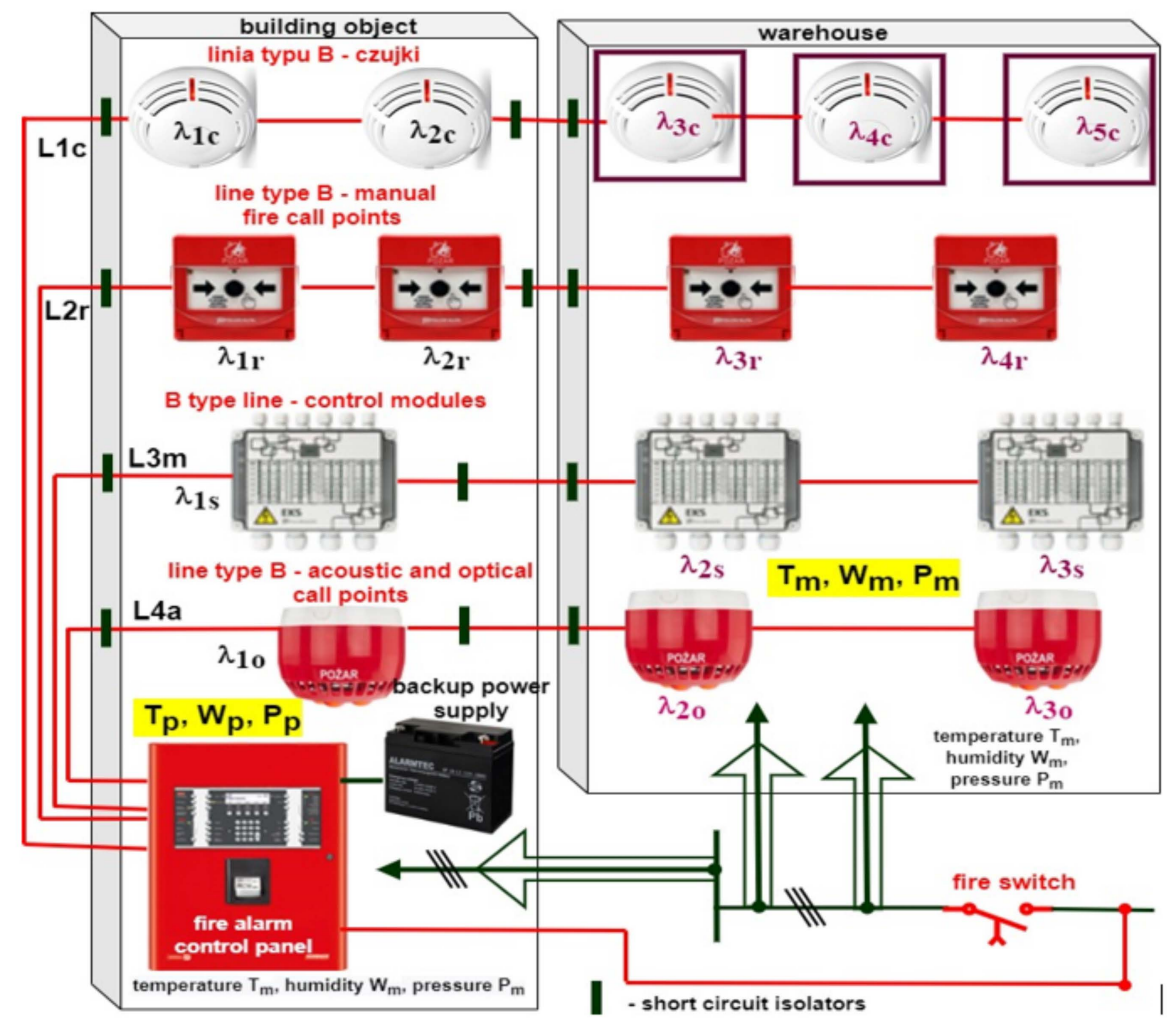

Figure 13. A focused FAS located in two different remote buildings-utility rooms, storage rooms, operation under various environmental conditions, where $\mathrm{T}_{\mathrm{pm}}$ - temperature, $\mathrm{W}_{\mathrm{pm}}$ - humidity, $\mathrm{P}_{\mathrm{pm}}$ - pressure.

The control modules located within a B-type line enable the control of, e.g., an audio warning system (AWS) or smoke exhaust devices and dampers [62,63]. The system consists of detection circuits, some of which have programmed detectors in coincidence systems, a control loop with a module controlling fire safety devices as well as technical and safety systems in the building and the storage room [22,29].

A signaling line with audio and optical signaling devices is also hooked-up to the FACU [36]. The FAS has a serial and parallel reliability structure [2,22]. Figure 14 is a graph showing the operating process of the FAS from Figure 13. 


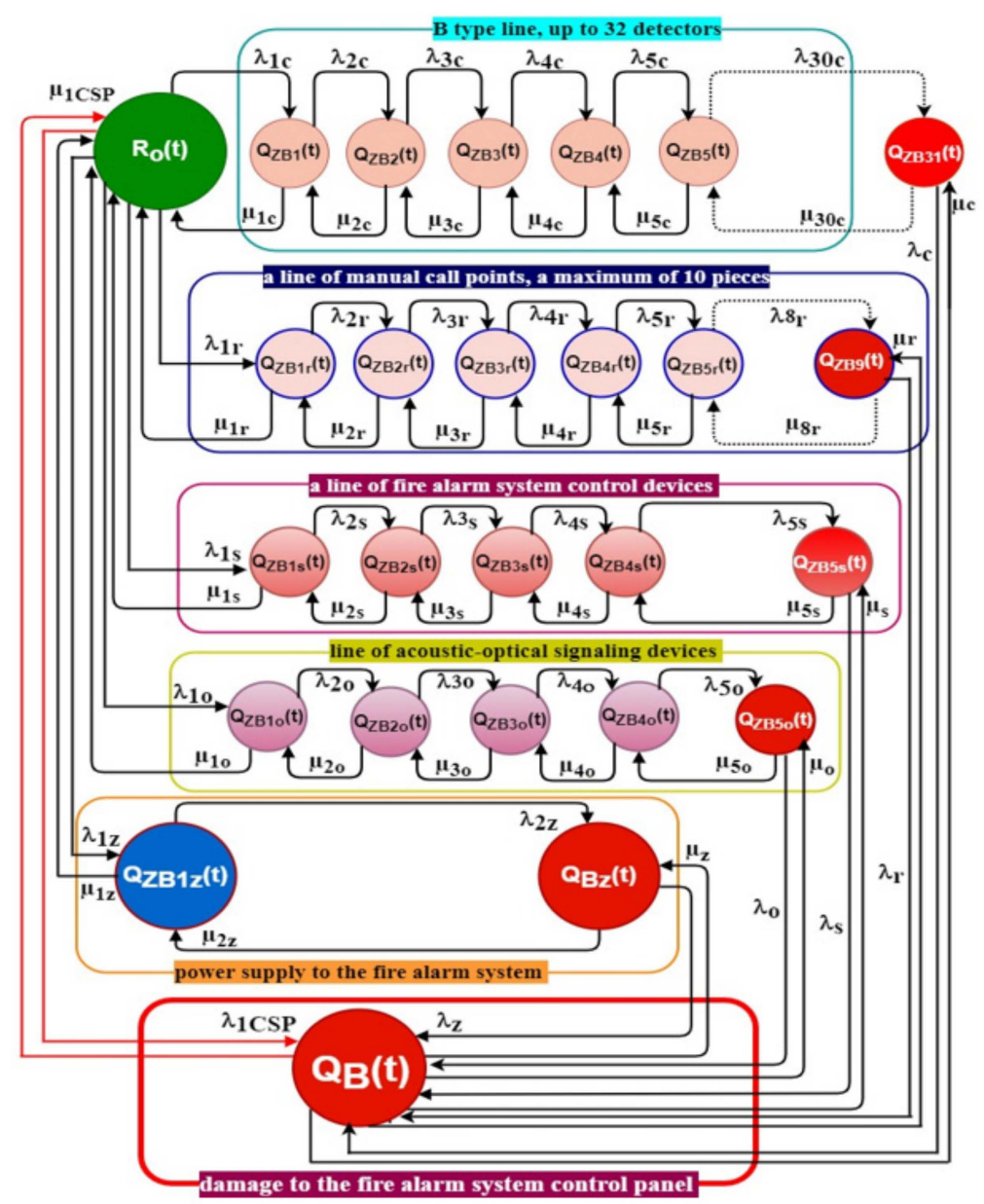

Figure 14. Operating states occurring in the course of operating a focused FAS with an addressable fire alarm control unit with detection and monitoring control on B-type radial lines, B-type audio and optical signaling device lines and MCPs, taking into account power supply unreliability-industrial mains and backup power supply.

Assuming certain baseline conditions, the focused FAS in question can be described using Expressions (8) and (9):

$$
\mathrm{R}_{0}(\mathrm{t})=1
$$

$$
\begin{gathered}
\mathrm{Q}_{\mathrm{ZB} 1}(0)=\mathrm{Q}_{\mathrm{ZB} 2}(0)=\mathrm{Q}_{\mathrm{ZB} 3}(0)=\mathrm{Q}_{\mathrm{ZB} 4}(0)=\mathrm{Q}_{\mathrm{ZB} 5}(0)=\mathrm{Q}_{\mathrm{ZB} 6}(0)=\mathrm{Q}_{\mathrm{ZB} 7}(0)=\mathrm{Q}_{\mathrm{ZB} 8}(0)=\mathrm{Q}_{\mathrm{ZB} 9}(0)=\mathrm{Q}_{\mathrm{ZB} 10}(0) \\
=\mathrm{Q}_{\mathrm{ZSA} 1}(0)=\mathrm{Q}_{\mathrm{ZSA} 2}(0)=\mathrm{Q}_{\mathrm{B}}(0)=0
\end{gathered}
$$

where $\mathrm{R}_{0}(\mathrm{t})$ - probability function for FAS staying in a state of full fitness $\mathrm{S}_{\mathrm{PZ}} ; \mathrm{Q}_{\mathrm{ZB} 1}(\mathrm{t})$ do

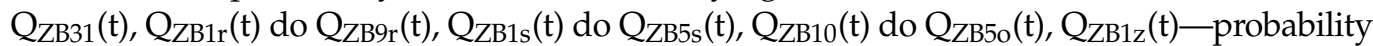
function for FAS staying in individual safety hazard states; $\mathrm{Q}_{\mathrm{B}}(\mathrm{t})$ - probability function for FAS staying in the safety unreliability state $\mathrm{S}_{\mathrm{B}} ; \mathrm{Q}_{\mathrm{Bz}}(\mathrm{t})$ - probability function for FAS staying in the safety unreliability state $S_{B}$ in the case of a power failure; $Q_{Z B 50}(t), Q_{Z B 5 s}(t), Q_{Z B 9 r}(t)$, $\mathrm{Q}_{Z B 31}$ - probability function for FAS staying in the safety unreliability state SB in the case of a failure in audio and optical signaling device line, controller line, B-type line with manual call point, radial detector line, $\lambda_{1 \mathrm{CSP}}$-intensity of transition from a state of full fitness SPZ to a state of safety unreliability $\mathrm{S}_{\mathrm{B}} ; \mu_{1 \mathrm{CSP}}$-intensity of transition from a state of safety unreliability SB to a state of full fitness $\mathrm{S}_{\mathrm{PZ}} ; \lambda_{1 \mathrm{c}}, \lambda_{2 \mathrm{c}}, \lambda_{3 \mathrm{c}}, \ldots, \lambda_{1 \mathrm{r}}, \lambda_{2 \mathrm{r}}, \lambda_{3 \mathrm{r}}, \ldots, \lambda_{1 \mathrm{~s}}, \lambda_{2 \mathrm{~s}}, \lambda_{3 \mathrm{~s}}$, $\ldots, \lambda_{10}, \lambda_{20}, \lambda_{30}, \ldots$, , intensity of transitions from a state of full fitness SPZ or a state of safety hazard $\mathrm{S}_{\mathrm{ZB}}$ to a state of safety unreliability $\mathrm{Q}_{\mathrm{B}}(\mathrm{t}), \mathrm{S}_{\mathrm{B}}$-as per the designations in Figure $14 ; \mu_{1 c}, \mu_{1 c}, \mu_{3 c}, \ldots, \mu_{1 r}, \mu_{1 r}, \mu_{3 r}, \ldots, \mu_{1 s}, \mu_{1 s}, \mu_{3 s}, \ldots, \mu_{1 o}, \mu_{1 o}, \mu_{3 o}, \ldots$-intensity of transitions from a state of safety hazard $\mathrm{S}_{\mathrm{ZB}}$ to a state of full fitness $\mathrm{S}_{\mathrm{PZ}}$, from a state of 
safety unreliability to a state of safety hazard or a state of safety hazard to a state of full fitness $R_{0}(t)$, as per the designations in Figure 14 .

Just like in Figure 13, the probability for an FAS staying in individual safety hazard, safety unreliability and full fitness states, as well as the transition intensities and recovery values were conducted using specialized BlockSim computing software by ReliaSoft $[2,58]$. This software enables simulations, studying reliability and calculating system availability. It also allows one to conduct various analyses in this regard [22,64,65]. The software offers appropriate graphical interface, which enables the modelling of complex systems (also other technical structures) and processes using relevant reliability block diagrams and fault tree analysis or a combination of both aforementioned approaches. It also offers separate process flow modules and Markov diagrams that are used to conduct the simulations [7,42].

State-discrete and time-continuous Markov chains for the focused FAS, as shown in Figure 14, can be described as a graph. In such a case, the transitions between individual states are defined by (fixed) transition intensities determined for the system in question (Figure 13). It is common to use time-continuous Markov chains to analyze the issue of reliability or, e.g., system A availability [2,7]. This can be described using a set of ordinary differential equations. In such a case, each differential equation represents a change in the probability of an FAS staying in a specified state (Expression (10)) [7,22]:

$$
\frac{d P_{j}}{d t}=\sum_{l=1}^{n} \lambda_{1 j} P_{1}-\sum_{l=1}^{n} \lambda_{j 1} P_{j}
$$

where $n$-number of considered states of a focused FAS; $\mathrm{P}_{\mathrm{j}}$ - probability of the considered FAS to stay in a distinguished state $\mathrm{j} ; \mathrm{P}_{1}$ - probability of the considered FAS to stay in a distinguished state $1 ; \lambda_{1 j}$-intensity of FAS's transition from state 1 to state $j$; $\lambda_{j l}$-intensity of a FAS' transition from state $\mathrm{j}$ to state 1.

The conditions for solving differential equations to determine FAS reliability and other security indices always result from the initial values for the probability of a system staying in each of the distinguished states. In the case of this focused FAS, the initial system states were described by Expression (3). Figure 14 shows the migration of possible states for a focused FAS with B-type open lines for detectors, MCPs and control modules, without sending alarm and damage signals to the PSP (respective graph for a focused FAS model from Figure 12)-graph printout from the BlockSim diagram [2,32].

Taking into account the determined damage $\lambda$ and recovery $\mu$ intensities relative to individual elements and devices of a focused FAS shown in Figure 14, it is possible to determine specific security indices for the operating process of this system. After commissioning and first start-up, an FAS operated within a given critical infrastructure facility is in a state of fitness, $R_{0}(t)=1$, which means that all elements and FACUs are efficient. At the time $t=0(s)$, the probability of a focused FAS staying in the state $R_{0}(t)=1$ (Figure 15), while the probability of staying in the state $\mathrm{Q}_{\mathrm{B}}(\mathrm{t})$ (safety unreliability) (Figure 16) is equal to zero. As the operation time passes, the $R_{0}(t)$ and $Q_{B}(t)$ values change. Value $R_{0}(t)$ decreases, as in Figure 16 , at a time $[0,2400 \mathrm{~h}]$; this is the beginning of the operating process.

Later on, the function waveform has a constant value equal to 0.9945 , while the value of function $\mathrm{Q}_{\mathrm{B}}(\mathrm{t})$ grows accordingly (Figure 17). It stabilizes after a time equal to $35.04(\mathrm{~h})$, when $\mathrm{Q}_{\mathrm{B}}(\mathrm{t})=3.4 \cdot 10^{-5}$. A very important issue at the beginning of the operating process is to determine the values of individual $Q_{Z B}$ (safety hazard) functions for individual B-type detection lines hooked-up to FACU. Calculating these values will enable the impact of individual detection lines on the value of $R_{0}(t)$ to be determined for the entire system, or system fitness in other words. 


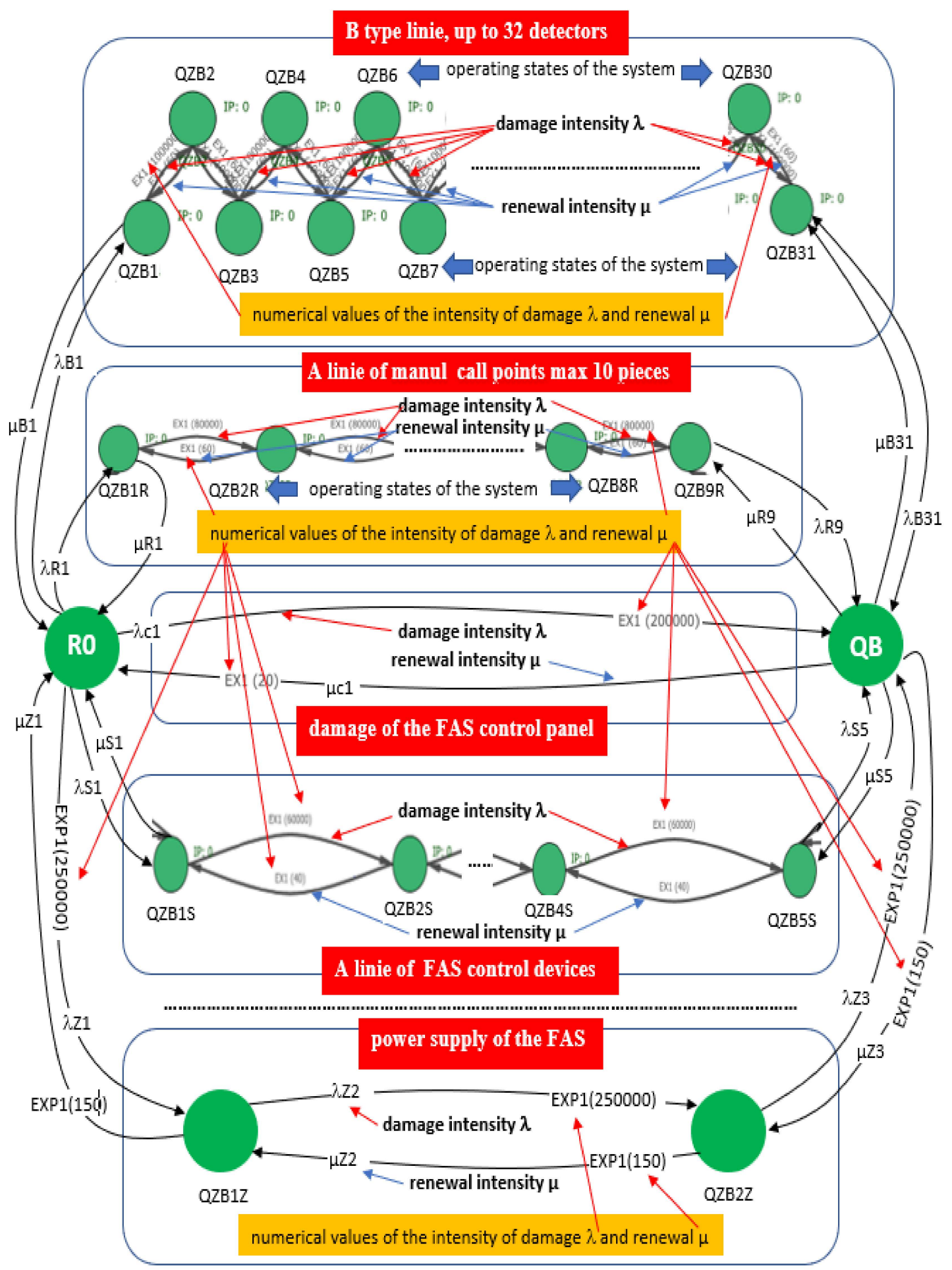

Figure 15. Migration of possible states for a focused FAS with B-type open lines for detectors, MCPs and control modules, without sending alarm and damage signals to the State Fire Service (graph printout from the BlockSim diagram). 


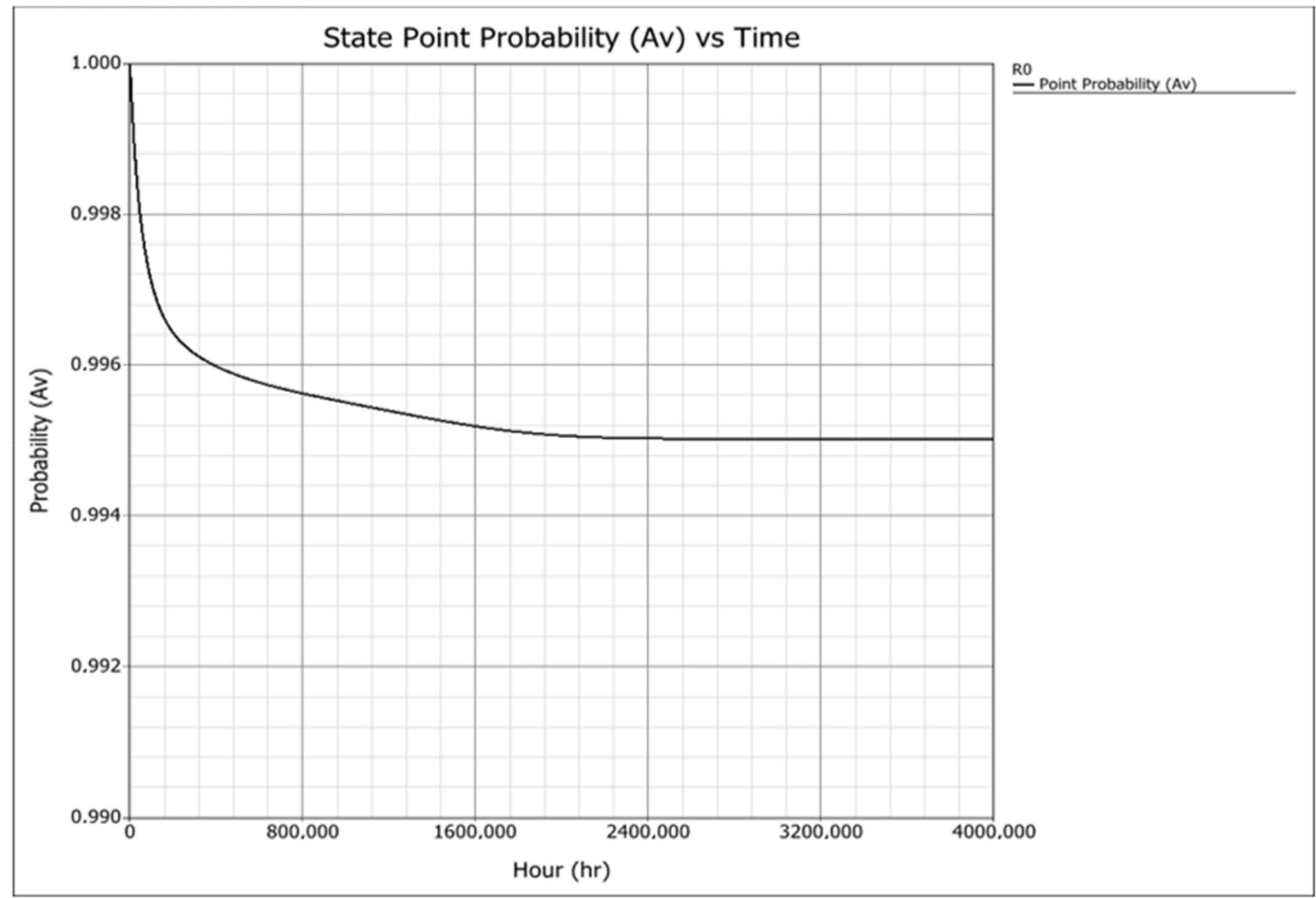

Figure 16. Probability for a focused FAS to stay in the state $R_{0}(t)$ with B-type open lines, without notifying the $P_{S P}$, as a function of time (study based on computational data from the BlockSim software).

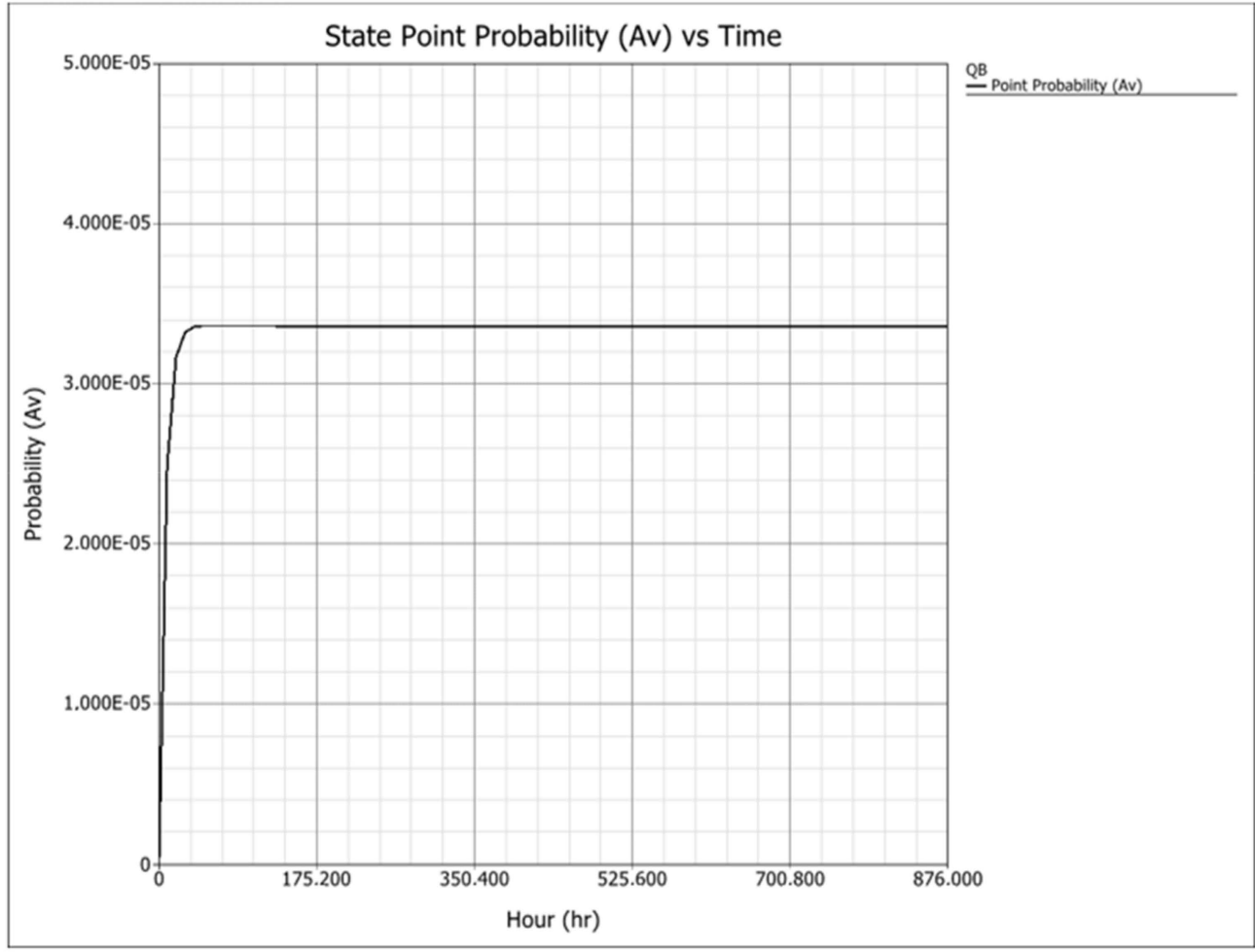

Figure 17. Probability of a focused FAS staying in the state $Q_{B}$-failure (unreliability) for the state $S_{0}$-B - type open line system, without notifying the PSP, as a function of time (study based on computational data from the BlockSim software).

After the entire FAS is activated and switches to the monitoring mode, which is the basic operation, the dominant state occurring at the initial moments of operation is state $\mathrm{Q}_{\mathrm{ZB1}}(\mathrm{t})$, which occurs within the B-type detection line. At the initial period of the FAS operation, this function increases $Q_{Z B 1}(t)$ - at $t=9 \mathrm{~h}$, the value of the function is $8.35 \cdot 10^{-5}$ 
(Figure 17), while after $10 \mathrm{~h}$ of FAS operation, this value is $\mathrm{Q}_{\mathrm{ZB} 1}(\mathrm{t})=0.000162747$. Other safety hazard states occurring within other detection lines connected to FACU reach low values (Figure 18). Please note the slow increase of all safety hazard functions for individual detection lines connected to FACU at the initial operation period, i.e., up to a maximum of $180 \mathrm{~h}$ (Figure 18). This corresponds approximately to seven first days of the FAS operating process. This is a so-called "breaking-in process" or the "infancy", which applies to all technical, mechanical, electrical or electronic objects. The system in question is electronic, since all FAS devices contain appropriately connected and polarized electronic elements and spaces arranged on PCBs, encased in a special housing, fireproof most usually, e.g., detectors, modules, MCPs or audio and optical signaling devices. The percentage share and value of individual safety hazard states that have the potential to occur within individual detection lines connected to a FACU are presented in Figures 19 and 20a-c, respectively. Figure 21 shows a graph with the $\%$ share of individual components in a safety hazard state $\mathrm{Q}_{\mathrm{ZB}}(\mathrm{t})$, for a line with connected detectors (max 32). The highest \% share among individual components for the initial operation stage, i.e., from starting the FAS up to $9 \mathrm{~h}$, is achieved by component $\mathrm{Q}_{\mathrm{ZB} 1}(\mathrm{t})$. It amounts to as much as $97 \%$ of the value of all components. The $\%$ share of all components $Q_{Z B 1-31}(t)$ within the operating process constantly changes.

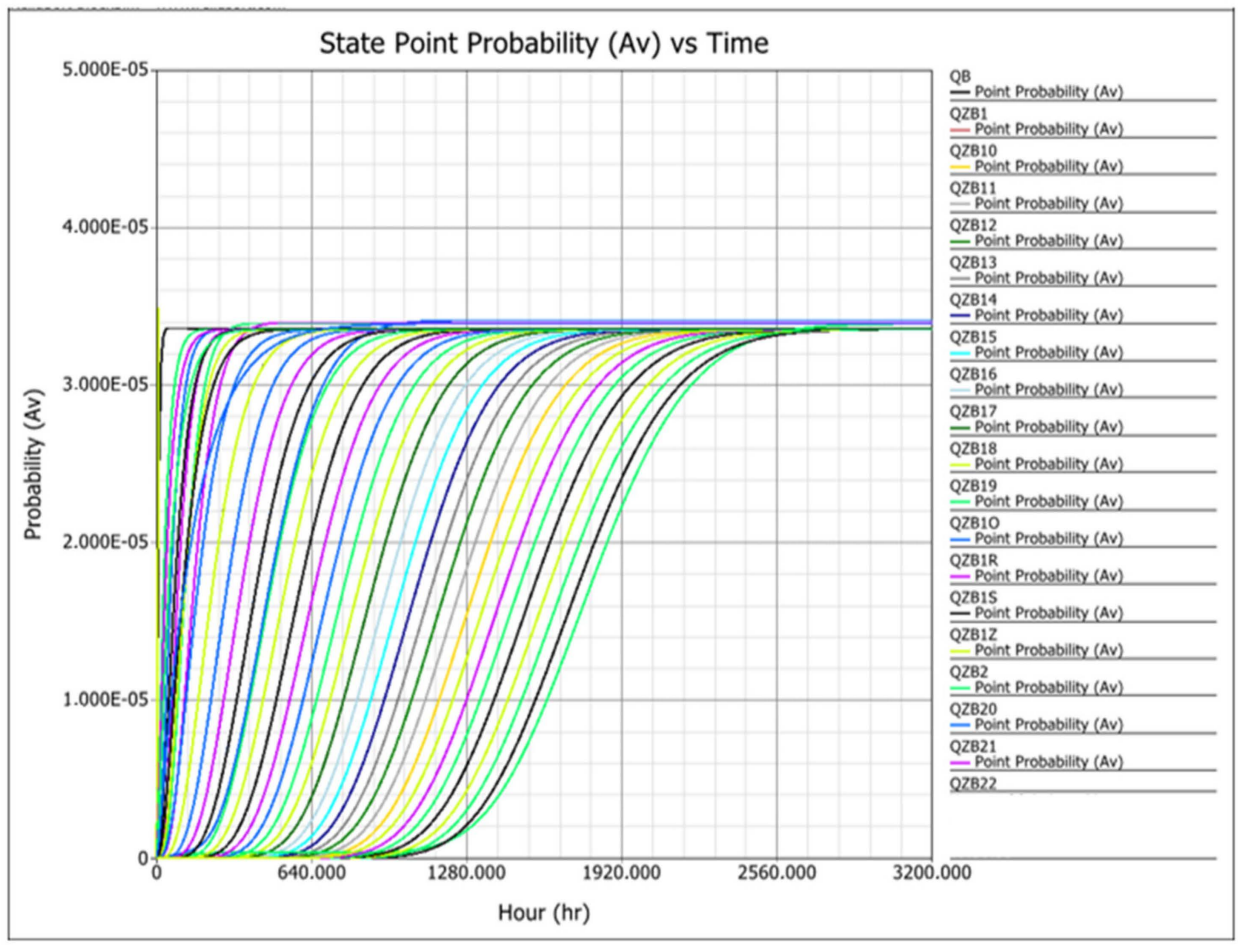

Figure 18. Probability of an FAS staying in distinguished safety hazard states $Q_{Z B}(t)$ in the case of the system in question. Zonal (partial) availability coefficients for separated technical states of a focused FAS $\mathrm{Q}_{\mathrm{B}}, \mathrm{Q}_{\mathrm{ZB} 1}, \mathrm{Q}_{\mathrm{ZB} 2}, \mathrm{Q}_{\mathrm{ZB} 3}, \ldots, \mathrm{Q}_{\mathrm{ZB} 1 \mathrm{r}}, \mathrm{Q}_{\mathrm{ZB} 2 \mathrm{r}}, \mathrm{Q}_{\mathrm{ZB} 3 \mathrm{r}}, \ldots, \mathrm{Q}_{\mathrm{ZB} 1 \mathrm{~s}}, \mathrm{Q}_{\mathrm{ZB} 2 \mathrm{~s}}, \mathrm{Q}_{\mathrm{ZB} 3 \mathrm{~s}}, \ldots, \mathrm{Q}_{\mathrm{ZB} 1 \mathrm{o}}, \mathrm{Q}_{\mathrm{ZB} 1 \mathrm{o}}$, i.e., safety unreliability and hazard. The figure does not show state $R_{0}(t)$ (for $t=0 R_{0}(t)=1$ ) (study based on computational data from the BlockSim software). 


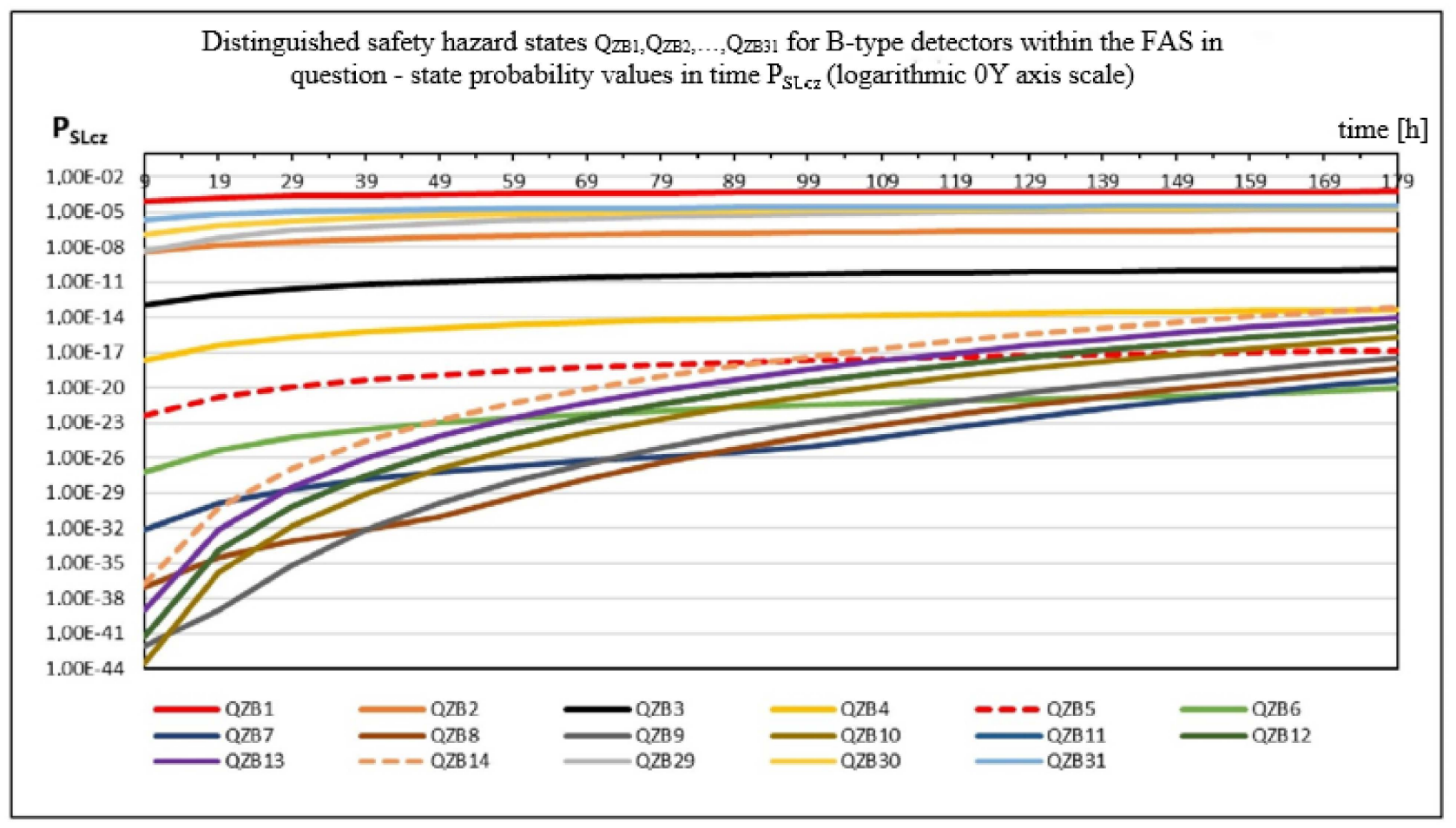

Figure 19. Zonal (partial) availability coefficients for separated technical states of a focused $F A S Q_{B}, Q_{Z B 1}, Q_{Z B 2}, Q_{Z B 3}$, ... $, \mathrm{Q}_{Z B 29}, \mathrm{Q}_{Z \mathrm{ZB} 30}, \mathrm{Q}_{\mathrm{ZB} 31}$-safety hazard indices for a B-type detector line (own study).

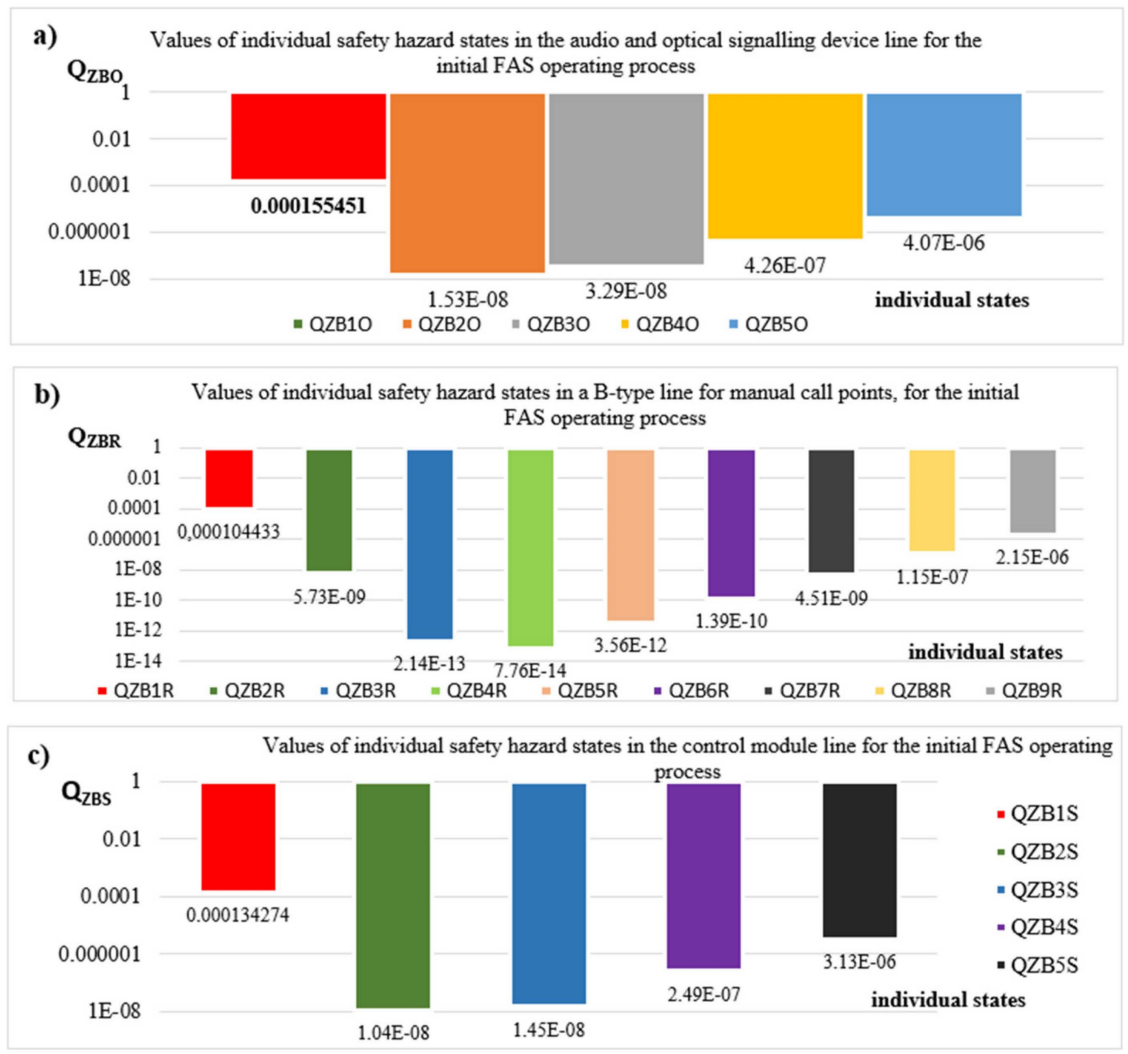

Figure 20. Values of individual safety hazard states in a focused FAS, for individual B-type lines of the system: (a) audio and optical signaling line, (b) manual call point line, (c) control module line (own study). 


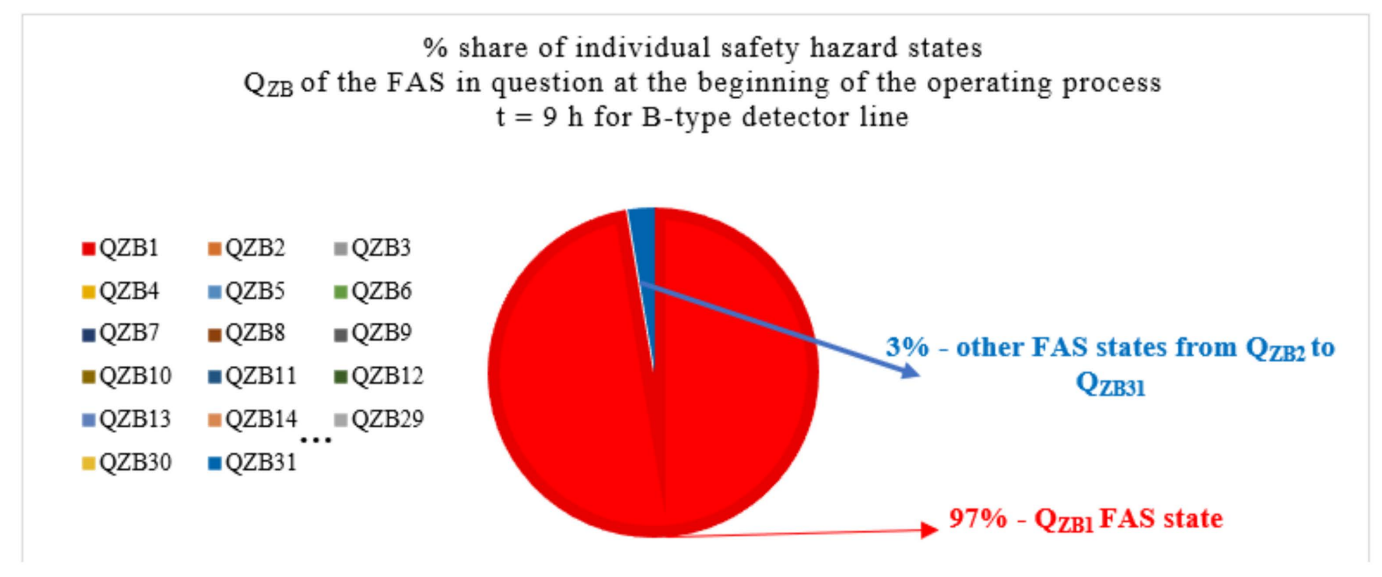

Figure 21. Percent share of individual safety hazard states $Q_{Z B}$ of the FAS in question, at the beginning of system operation, for $\mathrm{t}=9 \mathrm{~h}$ (own study).

Figure 20a-c shows the values of individual safety hazard states $\mathrm{Q}_{\mathrm{ZB}}(\mathrm{t})$ in a focused FAS, as in Figure 13, for individual B-type detection lines, which means audio and optical signaling device lines, manual call point lines and control module lines. The highest value is reached by the safety hazard component $\mathrm{Q}_{Z B 1 O}(t)=0.000155451$, i.e., a line with optical and audio signaling devices. Signaling devices are operated under varying environmental conditions, external or internal, and when the alarm is triggered, they consume significant amounts of electricity from the power supply or battery bank, constituting backup power supply sources. They consume power also when monitoring. It is used to diagnose, e.g., FACU-device connection continuity, i.e., to determine the absence of a short circuit or open-circuit of the power supply line. Individual components of the safety hazard $\mathrm{Q}_{\mathrm{ZB}}(\mathrm{t})$ reach different values (Figure 21). This difference is sometimes significant, e.g., $\mathrm{Q}_{\mathrm{ZB1O}}(\mathrm{t})=0.000155451$, and $\mathrm{Q}_{\mathrm{ZB2O}}(\mathrm{t})=1.53 \cdot 10^{-8}$, which means that some components are dominant within the operating process, while other are negligible at the initial operating stage. This tells a given FAS operator which detection lines and elements within such a bus should be given special attention in terms of the operating process at its initial stage. In order to better illustrate individual safety hazard components $\mathrm{Q}_{\mathrm{ZB}}(\mathrm{t})$ on detection lines connected to the FACU, the $0 \mathrm{Y}$ axis in Figure 20a-c has a logarithmic scale. Please note a certain regularity in the graphs in Figure 20a-c; the second or third component of safety hazard $Q_{Z B}(t)$ reaches a minimum value, e.g., $\mathrm{Q}_{\mathrm{ZB} 2 \mathrm{O}}(\mathrm{t})=1.53 \cdot 10^{-8}, \mathrm{Q}_{\mathrm{ZB} 4 \mathrm{R}}(\mathrm{t})=7.76 \cdot 10^{-14}$ or $\mathrm{Q}_{\mathrm{ZB} 2 \mathrm{~S}}(\mathrm{t})=1.04 \cdot 10^{-8}$.

\section{Conclusions}

FASs are some of the most important electronic security systems operated in critical infrastructure facilities or the so-called intelligent buildings. FAS devices or elements, unlike the rest of electronic alarm systems, are governed by the Regulation of the European Parliament and of the Council (EU) No. 305/2011 of 9 March 2011 (CPR). For all FASs operated in facilities, this means that elements or devices constituting components of such systems are treated similarly to building products, e.g., a floor beams and building partitions (walls, doors, windows, etc.) that are permanently embedded into a given structure. Due to their function in a building, they are considered to be very crucial to safety, fire-related in this case. This is why it is very important to ensure operational reliability of an FAS within a given facility and to ensure a low (zero) probability of a false alarm. Appropriate technical and organizational solutions are applied in relation to these two very important issues. The article discussed two various FAS structures. Due to the scope of conducted tasks and fire controls, the reliability and operational structure of such FASs is most usually mixed.

FAS designs utilize all available organizational solutions and technical measures aimed at increasing reliability, e.g., redundancy, backups, etc. This article presents the 
results of operating process tests involving selected FASs and the determined intensity values for $\lambda$ damage and $\mu$ recovery for selected elements and components of this system. The authors developed models of two FASs operated in critical infrastructure facilities. An operational and reliability analysis was conducted for selected system models, used later as a base to distinguish various operational states. Developed operating process models and the determined real values of $\lambda$ and $\mu$ intensities enabled operational safety process indices to be determined for these systems. The A availability coefficient for a simple system consisting of a FACU and two detectors amounted to 0.999098569 . This means that an FAS operated throughout the year is fit for $8752.104 \mathrm{~h}$ (or $99.91 \%$ of the entire year). Due to their complexity, the calculations for the second FAS, as in Figure 12, were conducted using the BlockSim simulation software by ReliaSoft. The FAS fitness probability $\mathrm{R}_{0}(\mathrm{t})$ at the initial operating process decreases over time [0, $\left.2400 \mathrm{~h}\right]$; however, its further waveform has a constant value $R_{0}(t)=0.9945$. The authors of the article determined the values of individual $\mathrm{Q}_{Z B}$ (safety hazard) functions for individual B-type detection lines hooked-up to FACU. Calculating individual $Q_{Z B}$ functions enables determination of the impact of B-type detection lines on the value of $R_{0}(t)$ of the entire FAS, or system fitness in other words. Individual safety hazard functions for selected detection lines increase and stabilize after an operation time of $180 \mathrm{~h}$.

This corresponds approximately to seven first days of the FAS operating process. This is a so-called "breaking-in process" or FAS "infancy", where users should pay particular attention to the operation of such an electronic system. All coefficients of the so-called zonal (partial) availability associated with safety hazard functions within the further operating process stabilize at constant levels. Quite often, the differences between individual FAS safety hazard functions are high, e.g., $\mathrm{Q}_{\mathrm{ZB1O}}(\mathrm{t})=0.000155451$, and $\mathrm{Q}_{\mathrm{ZB2O}}(\mathrm{t})=1.53 \cdot 10^{-8}$. For an FAS operator, this means that some components of the operating process associated with unfitness are dominant, while others, occurring within the initial operating process, are negligible. With the knowledge of such operating data, an FAS user knows which detection lines and elements within such a bus should be given special attention in terms of the operating process at its initial stage.

Author Contributions: Conceptualization, J.P., K.J. and S.D.; methodology, K.J., J.P. and S.D.; validation, J.P.; K.J. and J.B.; formal analysis, J.P., K.J. and S.D.; investigation, J.P., K.J. and S.D.; resources, J.P., K.J., S.D. and J.B.; data curation, K.J., J.P., S.D. and J.B.; writing-original draft preparation, K.J., J.P., S.D. and J.B.; writing-review and editing, J.P., K.J., S.D. and J.B.; visualization, K.J. and J.P.; supervision, J.P. and K.J.; project administration, J.P. and K.J. All authors have read and agreed to the published version of the manuscript.

Funding: This research received no external funding.

Institutional Review Board Statement: Not applicable.

Informed Consent Statement: Not applicable.

Data Availability Statement: Not applicable.

Conflicts of Interest: The authors declare no conflict of interest.

\section{List of Important Abbreviations and Symbols}

$\begin{array}{ll}\text { AWS } & \text { Audio Warning Systems } \\ \text { CPR } & \text { Council Parliament Regulation } \\ \text { PSP } & \text { State Fire Service } \\ \text { FACU } & \text { Fire Alarm Control Unit } \\ \text { ISL } & \text { Internal Supply Line } \\ \text { FFE } & \text { Fixed Fire Equipment } \\ \text { ARC } & \text { Alarm Receiving Centre } \\ \text { GSS } & \text { Gas Suppression System } \\ \text { CCTV } & \text { Closed-Circuit TV } \\ \text { ACS } & \text { Access Control System }\end{array}$




$\begin{array}{ll}\text { IDS } & \text { Intrusion Detection System } \\ \text { ADSTD } & \text { Alarm and Damage Signal Transmission Device } \\ \lambda & \text { Intensities of Damage } \\ \mu & \text { Intensities of Repairs } \\ A & \text { Availability Coefficient } \\ \text { MCP } & \text { Manual Call Points } \\ \mathrm{Q}_{\mathrm{ZB}}(\mathrm{t}) & \text { Safety Hazard States } \\ \mathrm{R}_{\mathrm{O}}(\mathrm{t}) & \text { State of Full Fitness } \\ \mathrm{Q}_{\mathrm{B}}(\mathrm{t}) & \text { State of Safety Unreliability } \\ \mathrm{A} & \text { Detection Circuit } \\ \mathrm{B} & \text { Radial Line Connected to a Fire System Control Unit } \\ \mathrm{US} & \text { Control Devices on Detection Line } \\ \mathrm{P}_{\mathrm{S} 1 S 2} & \text { Probability of Transition Between State } \mathrm{S}_{1} \text { and } \mathrm{S}_{2} \\ \mathrm{P}_{\mathrm{S} 1} & \mathrm{P}_{\mathrm{s} 1} \text { probability of the FAS remaining in the distinguished states } \mathrm{S}_{1} \\ \mathrm{M}_{\mathrm{PZ}} & \text { Mean Probability of Staying in a State of Full Fitness } \\ \mathrm{M}_{\mathrm{ZB}} & \text { Mean Probability of Staying in a State of Safety Unreliability } \\ \mathrm{M}_{\mathrm{Z}} & \text { Mean Probability of Staying in a State of Safety Hazard }\end{array}$

\section{References}

1. Regulation of Ministry of the Interior and Administration of Poland (MSWiA) of 7 June 2010 (Journal of Laws of the Republic of Poland No. 109, Item 719) Concerning Fire Protection of Buildings and Other Facilities and Grounds; Ministry of the Interior and Administration of Poland: Warsaw, Poland, 2021. Available online: https://sip.lex.pl/akty-prawne/dzu-dziennik-ustaw/ ochrona-przeciwpozarowa-budynkow-innych-obiektow-budowlanych-i-terenow-17626053 (accessed on 17 November 2021).

2. Klimczak, T.; Paś, J. Basics of Exploitation of Fire Alarm Systems in Transport Facilities; Military University of Technology: Warsaw, Poland, 2020.

3. Duer, S. Artificial neural network in the control process of object's states basis for organization of a servicing system of a technical objects. Neural Comput. Appl. 2012, 21, 153-160. [CrossRef]

4. Keding, L. An Optimization of Intelligent Fire Alarm System for High-Rise Building Based on anasys. In Intelligence Computation and Evolutionary Computation. Advances in Intelligent Systems and Computing; Du, Z., Ed.; Springer: Berlin/Heidelberg, Germany, 2013. [CrossRef]

5. Jafari, M.J.; Pouyakian, M.; Khanteymoori, A.; Hanifi, S.M. Reliability evaluation of fire alarm systems using dynamic Bayesian networks and fuzzy fault tree analysis. J. Loss Prev. Process. Ind. 2020, 67, 104229. [CrossRef]

6. Pati, V.B.; Joshi, S.P.; Sowmianarayana, R.; Vedavathi, M.; Rana, R.K. Simulation of Intelligent Fire Detection and Alarm System for a Warship. Def. Sci. J. 1989, 39, 79-94. [CrossRef]

7. Grabski, F. Semi-Markov Processes: Applications in System Reliability and Maintenance; Elsevier: Amsterdam, The Netherlands, 2015.

8. Polak, R.; Laskowski, D.; Matyszkiel, R.; Łubkowski, P.; Konieczny, Ł.; Burdzik, R. Optimizing the Data Flow in a Network Communication Between Railway Nodes. In Research Methods and Solutions to Current Transport Problems; Siergiejczyk, M., Krzykowska, K., Eds.; Springer: Cham, Switzerland, 2020; pp. 351-362. [CrossRef]

9. Duer, S. Examination of the reliability of a technical object after its regeneration in a maintenance system with an artificial neural network. Neural Comput. Appl. 2011, 21, 523-534. [CrossRef]

10. Cha, J.H.; Finkelstein, M. Point Processes for Reliability Analysis Shocks and Repairable Systems; Springer: Berlin/Heidelberg, Germany, 2018.

11. Kubica, P.; Boroń, S.; Czarnecki, L.; Węgrzyński, W. Maximizing the retention time of inert gases used in fixed gaseous extinguishing systems. Fire Saf. J. 2016, 80, 1-8. [CrossRef]

12. Zhao, H.; Schwabe, A.; Schläfli, F.; Thrash, T.; Aguilar, L.; Dubey, R.K.; Karjalainen, J.; Hölscher, C.; Cristoph, C.; Helbing, D.; et al. Fire evacuation supported by centralized and decentralized visual guidance systems. Saf. Sci. 2022, 145, 105451. [CrossRef]

13. Seong, G.; Kong, D.J.; Shengzhe, L.; Hakil, K. Fast fire flame detection in surveillance video using logistic regression and temporal smoothing. Fire Saf. J. 2016, 79, 37-43.

14. Morgan, A. Left Luggage, Automatic Fire Detection and the New Century. Fire Eng. J. 2000, 60, 37-39.

15. Suproniuk, M.; Paś, J. Analysis of electrical energy consumption in a public utility buildings. Przegląd Elektrotechniczny 2019, 95, 97-100. [CrossRef]

16. Bernardo, L.; Oliveira, R.; Tiago, R.; Pinto, P. A fire monitoring application for scattered wireless sensor networks: A peer-topeercross-layering approach. In Proceedings of the International Conference on Wireless Networks and Systems, Barcelona, Spain, 28-31 July 2007; pp. 28-31.

17. Stawowy, M.; Rosiński, A.; Paś, J.; Klimczak, T. Method of Estimating Uncertainty as a Way to Evaluate Continuity Quality of Power Supply in Hospital Devices. Energies 2021, 14, 486. [CrossRef]

18. Spertino, F.; Amato, A.; Casali, G.; Ciocia, A.; Malgaroli, G. Reliability Analysis and Repair Activity for the Components of 350 kW Inverters in a Large Scale Grid-Connected Photovoltaic System. Electronics 2021, 10, 564. [CrossRef] 
19. Rosiński, A. Reliability analysis of the electronic protection systems with mixed-Three branches reliability structure. In Reliability, Risk and Safety: Theory and Applications; Radim, B.C., Guedes, S., Martorell, S., Eds.; CRC Press/Balkema: London, UK, 2010; pp. 1637-1641. [CrossRef]

20. Dhillon, B.S. Applied Reliability and Quality, Fundamentals, Methods and Procedures; Springer: London, UK, 2006 ; p. 186.

21. Chiodo, E.; De Falco, P.; Di Noia, L. Challenges and New Trends in Power Electronic Devices Reliability. Electronics 2021, 10, 925. [CrossRef]

22. Paś, J.; Klimczak, T. Selected issues of the reliability and operational assessment of a fire alarm system. Ekspolatacja Niezazodn. Maint. Reliab. 2019, 21, 553-561. [CrossRef]

23. Zajkowski, K. Settlement of reactive power compensation in the light of white certificates. In Proceedings of the E3S Web of Conferences 19, UNSP 01037, Polanica Zdroj, Poland, 13-15 September 2017. [CrossRef]

24. Morgan, A. New fire detection concepts. Fire Saf. Eng. 2000, 7, 35-37.

25. Roman, D.; Saxena, S.; Bruns, J.; Valentin, R.; Pecht, M.; Flynn, D. A Machine Learning Degradation Model for Electrochemical Capacitors Operated at High Temperature. IEEE Access 2021, 9, 25544-25553. [CrossRef]

26. Lee, C.; Jo, S.; Kwon, D.; Pecht, M.G. Capacity-Fading Behavior Analysis for Early Detection of Unhealthy Li-Ion Batteries. IEEE Trans. Ind. Electron. 2021, 68, 2659-2666. [CrossRef]

27. Boroń, S.; Wegrzyński, W.; Kubica, P.; Czarnecki, L. Numerical modelling of the fire extinguishing gas retention in small compartment. Appl. Sci. 2019, 9, 663. [CrossRef]

28. Krzykowski, M.; Paś, J.; Rosiński, A. Assessment of the level of reliability of power supplies of the objects of critical infrastructure. In Proceedings of the IOP Conference Series: Earth and Environmental Science, Krakow, Poland, 14-17 November 2017; Volume 214, p. 012018. [CrossRef]

29. Da Penha, O.S.; Nakamura, E.F. Fusing light and temperature data for fire detection. In Proceedings of the IEEE Symposium on Computers and Communications (ISCC), Riccione, Italy, 22-25 June 2010; pp. 107-112.

30. Wang, C. Structural Reliability and Time-Dependent Reliability; Springer: Singapore, 2021.

31. Pas, J.; Rosinski, A.; Chrzan, M.; Bialek, K. Reliability-Operational Analysis of the LED Lighting Module Including Electromagnetic Interference. IEEE Trans. Electromagn. Compat. 2020, 62, 2747-2758. [CrossRef]

32. Serio, M.A.; Bonamno, A.S.; Knight, K.S.; Newman, J.S. Fourier Transform Infrared Diagnostics for Improved Fire Detection Systems. In Proceedings of the NIST Annual Conference on Fire Research, Gaithersburg, MD, USA, 28-31 October 1996.

33. So, A.T.P.; Chan, W.L. A computer-vision-based and fuzzy-logic-aided security and fire-detection system. J. Fire Technol. 1994, 30, 341-356. [CrossRef]

34. Rahardjo, H.A.; Prihanton, M. The most critical issues and challenges of fire safety for building sustainability in Jakarta. J. Build. Eng. 2020, 29, 101133. [CrossRef]

35. Cadena, J.E.; Osorio, A.F.; Torero, J.L.; Reniers, G.; Lange, D. Uncertainty-based decision-making in fire safety: Analyzing the alternatives. J. Loss Prev. Process. Ind. 2020, 68, 104288. [CrossRef]

36. Ding, L.; Ji, J.; Khan, F.; Li, X.; Wan, S. Quantitative fire risk assessment of cotton storage and a criticality analysis of risk control strategies. Fire Mater. 2020, 44, 165-179. [CrossRef]

37. Duer, S.; Zajkowski, K.; Płocha, I.; Duer, R. Training of an artificial neural network in the diagnostic system of a technical object. Neural Comput. Appl. 2012, 22, 1581-1590. [CrossRef]

38. Wu, H.; Wu, D.; Zhao, J. An intelligent fire detection approach through cameras based on computer vision methods. Process. Saf. Environ. Prot. 2019, 127, 245-256. [CrossRef]

39. Si, X.-S.; Zhou, D. A Generalized Result for Degradation Model-Based Reliability Estimation. IEEE Trans. Autom. Sci. Eng. 2014, 11, 632-637. [CrossRef]

40. Stawowy, M.; Perlicki, K.; Sumiła, M. Comparison of uncertainty multilevel models to ensure ITS Services. In Safety and Reliability-Theory and Applications: Proceedings of ESREL; Cepin, M., Radim, B., Eds.; CRC Press/Balkema: London, UK, 2017; pp. 2647-2652. [CrossRef]

41. Sharma, A.; Singh, P.K.; Kumar, Y. An integrated fire detection system using IoT and image processing technique for smart cities. Sustain. Cities Soc. 2020, 61, 102332. [CrossRef]

42. Paś, J. Shock a disposable time in electronic security systems. J. KONBiN 2016, 38, 5-31. [CrossRef]

43. Shuai, X.; Hao, C.; Feng, D.; Sihang, C. Online sensorless fault diagnosis and remediation strategies selection of transistors for power converter in SRD. IET Electr. Power Appl 2019, 13, 1553-1564. [CrossRef]

44. Klimczak, T.; Paś, J. Reliability and Operating Analysis of Transmission of Alarm Signals of Distributed Fire Signaling System. J. KONBiN 2019, 49, 165-174. [CrossRef]

45. Milic, M.; Ljubenovic, M. Arduino-Based Non-Contact System for Thermal-Imaging of Electronic Circuits. In Proceedings of the 2018 Zooming Innovation in Consumer Technologies Conference (ZINC), Novi Sad, Serbia, 30-31 May 2018 ; pp. 62-67. [CrossRef]

46. Paś, J. Operation of Electronic Transportation Systems; Publishing House University of Technology and Humanities: Radom, Poland, 2015.

47. Østrem, L.; Sommer, M. Inherent fire safety engineering in complex road tunnels—Learning between industries in safety management. Saf. Sci. 2021, 134, 105062. [CrossRef] 
48. Stawowy, M. Model for information quality determination of teleinformation systems of transport. In Safety and Reliability: Methodology and Applications, Proceedings of the 25th European Safety and Reliability Conference, ESREL 2015, Zurich, Switzerland, 10 September 2015; Nowakowski, T., Młyńczak, M., Jodejko-Pietruczuk, A., Werbińska-Wojciechowska, S., Eds.; CRC Press/Balkema: London, UK, 2015; pp. 1909-1914.

49. Rosiński, A. Modelling the Maintenance Process of Transport Telematics Systems; Publishing House Warsaw University of Technology: Warsaw, Poland, 2015.

50. Paś, J.; Klimczak, T. Modeling of the process of selected fire signaling systems. Diagnostyka 2019, 20, 81-88. [CrossRef]

51. Joglar, F. Reliability, Availability, and Maintainability. In SFPE Handbook of Fire Protection Engineering; Hurley, M., Ed.; Springer: New York, NY, USA, 2016; pp. 2875-2940.

52. Tostado-Véliz, M.; Bayat, M.; Ghadimi, A.A.; Jurado, F. Home energy management in off-grid dwellings: Exploiting flexibility of thermostatically controlled appliances. J. Clean. Prod. 2021, 310, 127507. [CrossRef]

53. Hulida, E.; Pasnak, I.; Koval, O.; Tryhuba, A. Determination of the Critical Time of Fire in the Building and Ensure Successful Evacuation of People. Period. Polytech. Civ. Eng. 2019, 63, 308-316. [CrossRef]

54. Kaniewski, P.; Smagowski, P.; Konatowski, S. Ballistic Target Tracking with Use of Cinetheodolites. Int. J. Aerosp. Eng. 2019, 2019, 3240898. [CrossRef]

55. Idris, A.M.; Rusli, R.; Burok, N.A.; Nabil, N.H.M.; Ab Hadi, N.S.; Karim, A.H.M.A.; Ramli, A.F.; Mydin, I. Human factors influencing the reliability of fire and gas detection system. Process. Saf. Prog. 2020, 39, e12116. [CrossRef]

56. Menon, S.; Chen, D.Y.; Osterman, M.; Pecht, M.G. Copper Trace Fatigue Life Modeling for Rigid Electronic Assemblies. IEEE Trans. Device Mater. Reliab. 2021, 21, 79-86. [CrossRef]

57. Paś, J.; Rosiński, A.; Wiśnios, M.; Majda-Zdancewicz, E.; Łukasiak, J. Electronic Security Systems. Introduction to the Laboratory; Military University of Technology: Warsaw, Poland, 2018.

58. Mahdipour, E.; Dadkhah, C. Automatic fire detection based on soft computing techniques: Review from 2000 to 2010 . Artif. Intell. Rev. 2012, 42, 895-934. [CrossRef]

59. Kozłowski, E.; Borucka, A.; Świderski, A. Application of the logistic regression for determining transition probability matrix of operating states in the transport systems. Ekspolatacja Niezawodn. Maint. Reliab. 2020, 22, 192-200. [CrossRef]

60. Duer, S. Assessment of the Operation Process of Wind Power Plant's Equipment with the Use of an Artificial Neural Network. Energies 2020, 13, 2437. [CrossRef]

61. Krepl, V.; Shaheen, H.I.; Fandi, G.; Smutka, L.; Muller, Z.; Tlustý, J.; Husein, T.; Ghanem, S. The Role of Renewable Energies in the Sustainable Development of Post-Crisis Electrical Power Sectors Reconstruction. Energies 2020, 13, 6326. [CrossRef]

62. Major, S.; Frickenstein, G. Reliability Theory with Applications to Preventive Maintenance; Llya Gertsbakh Springer: Berlin/Heidelberg, Germany, 2002; pp. 1111-1113; ISBN 3-540-67275-3. [CrossRef]

63. Duer, S.; Bernatowicz, D.; Wrzesień, P.; Duer, R. The diagnostic system with an artificial neural network for identifying states in multi-valued logic of a device wind power. In Communications in Computer and Information Science; Springer: Berlin, Germany, 2018; Volume 928, pp. 442-454.

64. Arias, S.; La Mendola, S.; Wahlqvist, J.; Rios, O.; Nilsson, D.; Ronchi, E. Virtual Reality Evacuation Experiments on Way-Finding Systems for the Future Circular Collider. Fire Technol. 2019, 55, 2319-2340. [CrossRef]

65. Rosiński, A.; Paś, J.; Łukasiak, J.; Szulim, M. Exploitation of electronic systems in building objects exposed to impact of strong electromagnetic pulses. In Proceedings of the 29th European Safety and Reliability Conference (ESREL), Hannover, Germany, 22-26 September 2019; Beer, M., Zio, E., Eds.; Research Publishing Services: Singapore, 2019; pp. 3320-3332. 